\title{
Phasic Dopamine Neuron Activity Elicits Unique Mesofrontal Plasticity in Adolescence
}

\author{
Surjeet Mastwal, ${ }^{1}$ Yizhou Ye, ${ }^{1}$ Ming Ren, ${ }^{1}$ Dennisse V. Jimenez, ${ }^{3}$ Keri Martinowich, ${ }^{3,4}$ Charles R. Gerfen, ${ }^{2}$ \\ and Kuan Hong Wang ${ }^{1}$ \\ ${ }^{1}$ Unit on Neural Circuits and Adaptive Behaviors, Genes Cognition and Psychosis Program, and 2Laboratory of Systems Neuroscience, National Institute of \\ Mental Health, National Institutes of Health, Bethesda, Maryland 20892, and ${ }^{3}$ Lieber Institute for Brain Development and ${ }^{4}$ Departments of Psychiatry and \\ Behavioral Sciences and Neuroscience, Johns Hopkins University School of Medicine, Baltimore, Maryland 21205
}

The mesofrontal dopaminergic circuit, which connects the midbrain motivation center to the cortical executive center, is engaged in control of motivated behaviors. In addition, deficiencies in this circuit are associated with adolescent-onset psychiatric disorders in humans. Developmental studies suggest that the mesofrontal circuit exhibits a protracted maturation through adolescence. However, whether the structure and function of this circuit are modifiable by activity in dopaminergic neurons during adolescence remains unknown. Using optogenetic stimulation and in vivo two-photon imaging in adolescent mice, we found that phasic, but not tonic, dopamine neuron activity induces the formation of mesofrontal axonal boutons. In contrast, in adult mice, the effect of phasic activity diminishes. Furthermore, our results showed that dopaminergic and glutamatergic transmission regulate this axonal plasticity in adolescence and inhibition of dopamine D2-type receptors restores this plasticity in adulthood. Finally, we found that phasic activation of dopamine neurons also induces greater changes in mesofrontal circuit activity and psychomotor response in adolescent mice than in adult mice. Together, our findings demonstrate that the structure and function of the mesofrontal circuit are modifiable by phasic activity in dopaminergic neurons during adolescence and suggest that the greater plasticity in adolescence may facilitate activity-dependent strengthening of dopaminergic input and improvement in behavioral control.

Key words: adolescence; dopamine; frontal cortex; in vivo imaging; optogenetics; phasic activity

\section{Introduction}

The mesofrontal dopaminergic circuit, which comprises dopaminergic projection neurons in the ventral midbrain and target neurons in the frontal cortex (FC) (Björklund and Dunnett, 2007), is engaged in control of motivated behaviors (Tzschentke, 2001; Grace et al., 2007). In addition, deficiencies in this circuit are associated with adolescent-onset psychiatric disorders in humans (Chambers et al., 2003; Winterer and Weinberger, 2004; Casey et al., 2010). Developmental studies in nonhuman primates and rodents suggest that the mesofrontal circuit exhibits a protracted maturation through adolescence (Kalsbeek et al., 1988; Rosenberg and Lewis, 1995). However, little is known

Received March 19, 2014; revised May 1, 2014; accepted May 26, 2014.

Author contributions: S.M., K.M., and K.H.W. designed research;S.M., Y.Y., M.R., and D.V.J. performed research; C.R.G. contributed unpublished reagents/analytic tools; S.M. and K.H.W. analyzed data; S.M., K.M., C.R.G., and K.H.W. wrote the paper.

This work was supported by National Institutes of Health-National Institute of Mental Health Intramural Research Programs (S.M., Y.Y., M.R., C.R.G., K.W.), Genes Cognition and Psychosis Program (K.W.), and NARSAD young investigator awards (S.M., M.R.). We thank T.R. Insel, D.R. Weinberger, R. Costa, and W. Chen for discussions and critical reading of the manuscript; K. Deisseroth for ChR2 plasmid; R. Costa and Z. He for technical advice; and A. Levin and K. Louhiranta for technical assistance.

The authors declare no competing financial interests.

Correspondence should be addressed to Kuan Hong Wang, Unit on Neural Circuits and Adaptive Behaviors, Genes Cognition and Psychosis Program, National Institute of Mental Health, National Institutes of Health, 35 Convent Drive, Room 2D913, Bethesda, MD 20892. E-mail: wkuan@mail.nih.gov.

DOI:10.1523/JNEUROSCI.1114-14.2014

Copyright $\odot 2014$ the authors $\quad 0270-6474 / 14 / 349484-13 \$ 15.00 / 0$ about whether dopamine neuron activity may elicit lasting effects on the structure and function of this circuit in adolescence.

Dopaminergic neurons fire action potentials in tonic or phasic modes (Grace et al., 2007). When animals are in a resting state, these neurons show tonic single-spike firing at frequencies lower than $10 \mathrm{~Hz}$ (Grace et al., 2007; Schultz, 2007). Phasic firing activities, which are bursts of spikes at frequencies $>10 \mathrm{~Hz}$, are correlated with rewarding, motivationally salient, or alerting signals (Schultz, 2007; Bromberg-Martin et al., 2010).

After the firing of dopamine neurons, dopamine is released from mesofrontal boutons, which are enlarged axonal structures containing a high level of the dopamine-synthesizing enzyme tyrosine hydroxylase (TH; Berger et al., 1991; Rosenberg and Lewis, 1995). Whereas the differentiation of frontal cortical layers and the adult-like topographic distribution of dopaminergic axons are established by the time of weaning ( 3 weeks) in rodents, dopaminergic boutons continue to develop through adolescence (Kalsbeek et al., 1988).

Mesofrontal dopaminergic input plays an important role in regulating the activity of frontal cortical neurons and psychomotor behaviors. Electrophysiologically, phasic stimulation of dopamine neurons in midbrain ventral tegmental area (VTA) evokes sustained neural activity in the adult FC (Lewis and O'Donnell, 2000; Lavin et al., 2005). Behaviorally, exposure to novel environments or psychostimulants such as amphetamine increases dopamine release and locomotor activity in rodents. Whereas 
activation of nucleus accumbens (NA) and its associated dopaminergic input facilitates this psychomotor response, activation of the mesofrontal circuit exerts an inhibitory effect (Tzschentke, 2001; Chambers et al., 2003).

To investigate whether dopamine neuron activity may modify the structure and function of the mesofrontal circuit, we used optogenetic methods to control the activity patterns of dopamine neurons. Our findings showed that, in adolescent mice, phasic dopamine neuron activity elicits lasting structural and functional changes in the mesofrontal circuit. Those changes include more boutons on dopaminergic axons in the FC, potentiated mesofrontal circuit activity, and suppressed psychomotor response, as revealed by in vivo two-photon imaging, electrophysiology, gene expression, and behavioral analysis. In contrast, in adult mice, even though VTA dopamine neurons are activated by optogenetic stimulation comparably to adolescent mice, the impacts of phasic activity on the mesofrontal circuit and psychomotor behavior are greatly diminished. These results reveal greater plasticity of the mesofrontal dopaminergic circuit in adolescence, which may facilitate activity-dependent strengthening of dopaminergic input and improvement in behavioral control.

\section{Materials and Methods}

Experimental animals. Heterozygous TH-Cre (Gong et al., 2007) and Arc-GFP (Wang et al., 2006) mice in the C57BL/6 strain were used in this study. Mice were normally housed in groups $(\sim 2-4$ mice per cage $)$ and maintained under a standard $12 \mathrm{~h}$ light/dark cycle. Adolescent $[\sim 4-5$ weeks old, postnatal days $28-42(\mathrm{P} 28-\mathrm{P} 42)]$ and adult $(\sim 2-4$ months old) mice were used for experiments. Experimental protocols were approved by the National Institute of Mental Health Animal Care and Use Committee and were in accordance with the National Institutes of Health Guidelines for the Care and Use of Laboratory Animals.

TH immunostaining in VTA and FC. Mice were perfused with $0.9 \%$ saline, followed by $4 \%$ paraformaldehyde (PFA) in PBS, and postfixed overnight in $4 \%$ PFA at $4^{\circ} \mathrm{C}$. Then, $70-\mu \mathrm{m}$-thick coronal sections were incubated with blocking solution containing $10 \%$ normal goat serum (NGS), $0.3 \%$ Triton X-100 in PBS, pH 7.4, at room temperature for $1 \mathrm{~h}$, followed by incubation in rabbit anti-TH antibody $(1: 10,000$, catalog \#AB152, RRID:AB_390204; Millipore; Di Salvio et al., 2010) with 5\% NGS in PBS overnight at $4^{\circ} \mathrm{C}$. Sections were then washed $3 \times(10 \mathrm{~min}$ each) with PBS, followed by incubation in Alexa Fluor 568-conjugated goat anti-rabbit IgG (1:100; Invitrogen) with 5\% NGS in PBS for $2 \mathrm{~h}$ at room temperature. Sections were washed again and mounted for imaging with a confocal laser-scanning microscope (FV1000; Olympus).

Labeling of VTA neurons with tetramethylrhodamine dextran. Tetramethylrhodamine (TRITC)-dextran (3000 MW, 10\% in PBS) was loaded into a glass micropipette (tip size $\sim 10-20 \mu \mathrm{m}$ ), and iontophoretically injected (10 $\mu$ A positive current, $200 \mathrm{~ms}$ pulse, $2 \mathrm{~Hz}$, for $10 \mathrm{~min}$ ) into the right VTA (4 injection sites, from bregma: AP $-3.1,-3.3$; ML 0.5; and DV 4.4, $4.5 \mathrm{~mm})$. Mice were housed for $2-3 \mathrm{~d}$ to allow for recovery and anterograde labeling of the axons. For each animal, the VTA was sectioned and immunostained with TH antibody to confirm the location of the injection site. The frontal cortical region imaged by two-photon microscopy in vivo was marked with fluorescent beads (Lumafluor) and immunostained with TH antibody. Animals in which there were no THcolabeled axons in the imaged frontal cortical region were not analyzed further.

Optogenetic labeling of VTA dopamine neurons. The pAAV-EF1a double-floxed hChR2(H134R)-EYFP-WPRE-HGHpA plasmid was kindly provided by K. Deisseroth at Stanford University. Serotype 1 recombinant adeno-associated viruses (AAVs) were made by the University of North Carolina (Chapel Hill, NC) Vector Core at a concentration of $1.5 \times 10^{12} / \mathrm{ml}$. AAV1.CAG.FLEX.EGFP.WPRE.bGH viral vector was purchased through Addgene and University of Pennsylvania (Philadelphia, PA) Vector Core based on a plasmid established by the Allen Brain Institute. AAV $(1 \mu \mathrm{l})$ was injected through a glass micropipette, which was connected to a $10 \mu \mathrm{l}$ Hamilton syringe and a syringe pump, into a single site (from bregma: AP -3.2, ML 0.5, and DV $4.5 \mathrm{~mm}$, for both preadolescent $(\sim \mathrm{P} 21)$ and adult mice). In addition, cannula guides were implanted over the same stereotaxic coordinates and secured with dental cement for optical fiber insertion. Animals were allowed to recover for $\sim 10-14 \mathrm{~d}$ for both age groups. For each animal, the VTA was sectioned after experiments to confirm the location of the cannula and the normal histology of labeled VTA cells. The extent of fluorescently labeled cells was typically $\sim 0.5 \mathrm{~mm}$ from the injection center in the anterior-posterior and medial-lateral directions and covered most of the VTA region. If the cannula tip went too deep and damaged labeled cells in the VTA or the tip was too far outside the VTA $(>1 \mathrm{~mm}$ above VTA or $>1 \mathrm{~mm}$ lateral from the midline), those animals were not analyzed further.

Light activation of VTA dopamine neurons. An optical fiber $(200 \mu \mathrm{m}$ in diameter; Thor Laboratories) was connected to a $473 \mathrm{~nm}$ solid-state laser diode (CrystaLaser) with $\sim 20 \mathrm{~mW}$ output from the fiber. To record light-evoked responses in VTA, the optical fiber was glued $\sim 0.5 \mathrm{~mm}$ above the tip of a tungsten microelectrode $(\sim 0.5 \mathrm{M} \Omega)$. This optoelectrode was then lowered into the VTA (from bregma: AP -3.2, ML 0.5, DV $4.5 \mathrm{~mm}$ ) of ChR2-EYFP AAV-injected TH-Cre mice under Avertin anesthesia. Tonic (1 Hz pulse train, $3 \mathrm{~ms} /$ pulse, 10 pulses/train, 1 train/ min for $10 \mathrm{~min}$ ) or phasic ( $50 \mathrm{~Hz}$ pulse train, $3 \mathrm{~ms} /$ pulse, 10 pulses/train, $1 \mathrm{train} / \mathrm{min}$ for $10 \mathrm{~min}$ ) light pulses were delivered to those mice. Local field potential responses to optical stimulation were recorded with an amplifier (Molecular Devices). The signals were band-pass filtered between 0.1 and $100 \mathrm{~Hz}$

To determine c-Fos expression in the VTA after phasic optical stimulation, mice were perfused $1 \mathrm{~h}$ after stimulation and c-Fos immunostaining was performed. Sections were incubated in 50\% ethanol in PBS for 30 $\mathrm{min}, 3 \%$ hydrogen peroxide for $10 \mathrm{~min}$, blocking solution for $1 \mathrm{~h}$ at room temperature, and rabbit anti-c-Fos antibody (1:5000, catalog \#PC38100UL, RRID: AB_213663; Millipore; Deng et al., 2010) with 5\% NGS in PBS overnight at $4^{\circ} \mathrm{C}$. Sections were then incubated in biotinylated goat-anti rabbit secondary antibody for $2 \mathrm{~h}$ (1:1000; Jackson ImmunoResearch), streptavidin-HRP for 30 min (1:2500, TSA cyanine kit; PerkinElmer), and TSA plus Cy3 amplification reagent (PerkinElmer).

Two consecutive coronal sections (each $80 \mu \mathrm{m}$ in thickness) containing the VTA region directly below the tip of optical fiber (from bregma: AP - 3.2, ML 0.5, and DV $4.5 \mathrm{~mm}$ ) in each animal were imaged using a $10 \times$ lens. Regions of interest covering the VTA $\left(0.89 \mathrm{~mm}^{2}\right.$ per section $)$ were drawn in the imaged sections according to the stereotaxic atlas (Paxinos and Franklin, 2004) with the investigator blinded with regard to experimental conditions. c-Fos ${ }^{+}$cell nuclei within these regions of interest were detected automatically by thresholding the images at 3 SDs above background, then selecting particles of $49-200 \mu \mathrm{m}^{2}$ in size using ImageJ. To determine the percentage of ChR2-EYFP ${ }^{+}$cells that are c-Fos $^{+}$, a $20 \times$ [numerical aperture (NA) 0.95 ] lens at $2 \times$ zoom was used to take 4 adjacent image stacks $\left(318 \times 318 \times 12 \mu \mathrm{m}^{3}\right)$ in each of these two brain sections. ChR2-YFP and c-Fos colabeling analysis was done manually by a human observer blinded to the experimental conditions. ChR2-EYFP labeling was on cell membrane and positive cells were identified in the green channel by searching through each slice of the 3D image stack. Each identified ChR2-YFP ${ }^{+}$cell was then examined for c-Fos nuclei expression within adjacent slices in the red channel of the 3D image stack.

In vivo imaging of mesofrontal axons. Adolescent ( $\sim 4-5$ weeks old) or adult ( $\sim 2-4$ months old) male mice were anesthetized using Avertin $(0.5$ $\mathrm{mg} / \mathrm{g}$ body weight) and placed on a stereotaxic apparatus. Cranial window surgery was performed similarly to a published protocol (Cao et al., 2013). A high-speed dental drill was used to thin the skull above the FC (from bregma: AP 1.0-3.0 mm, ML 0.3-1.3 mm, covering the M2/FrA region; Paxinos and Franklin, 2004). The thinned skull cap was removed with forceps to create a small $(\sim 2 \times 1 \mathrm{~mm})$ cranial window. The cranial window was filled with $2 \%$ agarose and ACSF, covered with a glass coverslip, and sealed with dental cement.

A two-photon microscope (FV1000; Olympus) was used to image the brain under the cranial window (excitation laser: $870 \mathrm{~nm}$ for TRITCdextran, $\sim 15-75 \mathrm{~mW} ; 920 \mathrm{~nm}$ for ChR2-EYFP and EGFP, $\sim 10-25$ $\mathrm{mW})$. A low-magnification image of the overall area containing labeled axons was first taken with a $20 \times$ water-immersion lens (NA 0.95). Mul- 
tiple image stacks ( $\sim 30-50$ slices, $159 \times 159 \mu \mathrm{m}^{2}$ per slice, $1 \mu \mathrm{m} z$-step) were then taken at $4 \times$ zoom at the center of this region $(50-300 \mu \mathrm{m}$ below pial surface) to follow all of the labeled axons continuously and in greater detail. The low-magnification image was used for realignment during the second imaging session and the high-magnification image stacks were taken again for comparison of axon morphology. For illustration purposes, $2 \mathrm{D}$ maximum-intensity projections of the $3 \mathrm{D}$ image stacks containing axonal segments of interest were used for all figures.

Axonal dynamics under running wheel and home cage conditions. After the first two-photon imaging session, animals were allowed to recover from anesthesia. They were then placed in the home cage or exposed to a running wheel (Med Associates) for $2 \mathrm{~h}$, anesthetized with isoflurane $(1.5 \%)$, and imaged for the second time. To confirm the engagement of the FC in the running wheel task, heterozygous Arc-GFP mice were used in these experiments. A similar increase in mesofrontal bouton formation was also confirmed in wild-type adolescent mice (home cage: $2.6 \pm$ $1.8 \%$, running wheel: $14.9 \pm 4.5 \% ; p<0.05, n=4$ mice for each group).

Axonal dynamics under optogenetic stimulation conditions. An optical fiber was inserted into an internal cannula with $\sim 0.5 \mathrm{~mm}$ protrusion and glued into place. The internal cannula containing the optical fiber was then inserted into the implanted cannula guide in ChR2-EYFP AAV- or EGFP AAV-injected TH-Cre mice. After the first two-photon imaging session, the animals were either not stimulated, stimulated with a tonic pattern ( $1 \mathrm{~Hz}$ pulse train, $3 \mathrm{~ms} /$ pulse, 10 pulses/train, $1 \mathrm{train} / \mathrm{min}$ for 10 min), or stimulated with a phasic pattern $(50 \mathrm{~Hz}$ pulse train, $3 \mathrm{~ms} /$ pulse, $10 \mathrm{pulses} /$ train, $1 \mathrm{train} / \mathrm{min}$ for $10 \mathrm{~min}$ ). These mice remained under constant isoflurane $(\sim 1.5 \%)$ anesthesia for $2 \mathrm{~h}$ before being imaged for the second time.

To evaluate the effects of neurotransmission on axonal plasticity, D2 receptor agonist quinpirole $(1 \mathrm{mg} / \mathrm{kg}$ ) or antagonist eticlopride $(0.5 \mathrm{mg} / \mathrm{kg}$; Zhang et al., 2009) was administered intraperitoneally $\sim 10$ min before phasic stimulation. The NMDA receptor antagonist CPP (3 $\mathrm{mg} / \mathrm{kg}$; Riekkinen et al., 1996) and the AMPA receptor antagonist CNQX (10 mg/kg; Bekar et al., 2008) were mixed together and administered intraperitoneally $\sim 20$ min before phasic stimulation.

Analysis of in vivo two-photon images. To determine bouton dynamics in time-lapse in vivo two-photon images, axons and boutons at each time point were first labeled automatically using scripts written in Matlab (Mathworks) and NIH ImageJ, blind with regard to experimental conditions. Axons were detected using line filters based on the Hessian Matrix (Sato et al., 1998; FeatureJ plugin in ImageJ), and thresholded at 2 SDs above background. Boutons were detected as bright swellings along axons that are larger than $0.5 \mu \mathrm{m}^{2}$ in size and have intensity values at least 2.5-fold brighter than the flanking axon backbone (Nishiyama et al., 2007; Holtmaat et al., 2009). The file names of each labeled images in a time series were randomly assigned, and a human observer blind to the imaging conditions aligned and verified the presence or absence of boutons in each image. The percentage of newly formed boutons is calculated as the number of boutons present at time point 2 but not at time point 1 , divided by the total number of boutons present at time point 1 . The percentage of eliminated boutons is calculated as the number of boutons present at time point 1 but not at time point 2 , divided by the total number of boutons present at time point 1 .

Electrophysiological recording in the FC. A cranial window above the FC (from bregma: AP 1.0-3.0 mm, ML 0.3-1.3 mm, covering the M2/FrA region; Paxinos and Franklin, 2004) was opened in ChR2-EYFP AAV injected TH-Cre mice of either sex under isoflurane $(\sim 1.5 \%)$ anesthesia. To record local field potentials in response to phasic stimulation of the VTA (Lewis and O'Donnell, 2000; Lavin et al., 2005), a glass micropipette $(\sim 2 \mathrm{MOhm})$ was inserted into the FC $(\sim 150-300 \mu \mathrm{m}$ from the pial surface in layer II/III). The recorded signals were bandpass filtered between 0.1 and $100 \mathrm{~Hz}$. The first session of VTA stimulation consisted of 10 trains of phasic light pulses $(50 \mathrm{~Hz}$ pulse train, $15 \mathrm{~ms} /$ pulse, 10 pulses/ train, 1 train/min for $10 \mathrm{~min}$ ). Afterward, the animal was kept under constant isoflurane $(\sim 1.5 \%)$ anesthesia for $2 \mathrm{~h}$, and then received identical stimuli in the second session.

In each stimulation session, the LFP signals in $2 \mathrm{~s}$ windows before and after the start of each light train were averaged across 10 sweeps of recordings. In the poststimulation time window, the absolute value of LFP
A
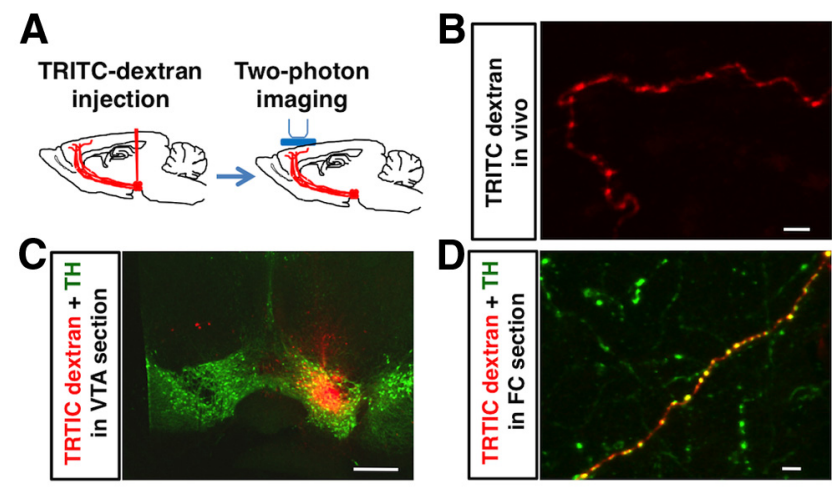

E

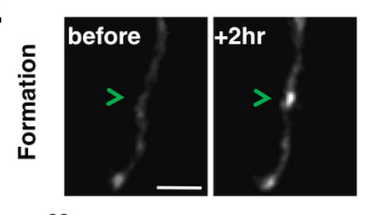

$\mathbf{F}$
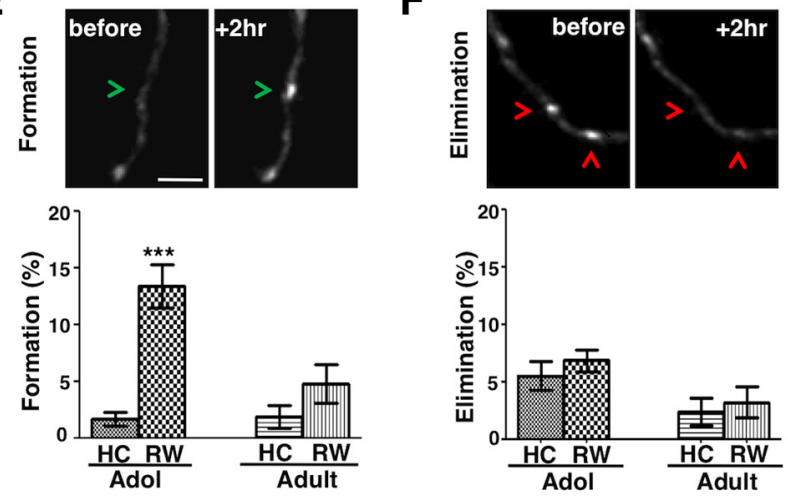

Figure 1. Wheel running enhances the formation of mesofrontal boutons in adolescent mice. $\boldsymbol{A}$, Diagram showing experimental conditions. $\boldsymbol{B}$, In vivo two-photon image of TRITCdextran (red)-labeled axon in the frontal cortex (M2 region, layers I-III). C, Confocal image of coronal midbrain section showing the overlap of injected TRITC-dextran (red) with the VTA dopamine neurons labeled by TH immunofluorescence (green). Scale bar, $500 \mu \mathrm{m}$. D, Confocal image of TRITC-dextran (red) labeled axon in a frontal cortical section immunostained for TH (green). $\boldsymbol{E}, \boldsymbol{F}$, Top, In vivo two-photon images showing examples of bouton formation ( $\boldsymbol{E}$, green arrowheads) and elimination ( $\boldsymbol{F}$, red arrowheads). Bottom, Percentage of boutons formed $(\boldsymbol{E})$ and eliminated $(\boldsymbol{F})$ under home cage $(\mathrm{HC})$ and running wheel $(\mathrm{RW})$ conditions in adolescent $(\sim 4-5$ weeks) and adult ( $\sim 2-4$ months) male mice heterozygous for an Arc-GFP gene expression reporter. For $\boldsymbol{E}_{,}^{* * *} p<0.001$, Bonferroni's posttest; ANOVA age-by-condition interaction, $F_{(1,19)}=9.89, p=0.005$. For $\boldsymbol{F}$, ANOVA age-by-condition interaction, $F_{(1,19)}=0.04$, $p=0.842 . n=6$ mice for each group except adult RW, where $n=5$. Scale bars: $\boldsymbol{B}, \boldsymbol{D}, \boldsymbol{E}, \boldsymbol{F}, 5$ $\mu \mathrm{m} ; \mathrm{C}, 500 \mu \mathrm{m}$.

shifts below the baseline was summed up to indicate the total amount of LFP response. In addition, the peak amplitude and the duration (the period when LFP signals were lower than the baseline by $>1.6 \times$ SDs) of negative LFP shifts were also examined.

To examine the higher frequency components in the LFP signals, we used Matlab (Mathworks) signal processing toolbox to calculate the spectrogram of the LFP signals in a period from $2 \mathrm{~s}$ before VTA stimulation to $3 \mathrm{~s}$ after. Based on the short-time Fourier-transform algorithm, spectral analyses were conducted for each $0.5 \mathrm{~s}$ sliding window ( $0.1 \mathrm{~s}$ step) in individual sweeps of LFP recordings. To summarize the long-lasting changes in high-frequency oscillations, the power spectral density calculated at $1 \mathrm{~s}$ post VTA stimulation was averaged over a high-frequency band ( $4-55 \mathrm{~Hz}, \theta$ to $\gamma$ oscillation range) for each subject and condition.

Home cage behavior and psychomotor responses. Male mice were randomly assigned to receive either ChR2-EYFP AAV or EGFP AAV injection in the midbrain. Mouse ID encoded conditions of viral injection. The same behavioral treatments were applied to all mice. Adolescent ( $\sim 4-5$ weeks $)$ and adult ( $\sim 2-4$ months) mice expressing either virus were stimulated first with phasic light pulses $(50 \mathrm{~Hz}$ pulse train, $3 \mathrm{~ms} /$ pulse, 10 pulses/train, 1 train/min for $10 \mathrm{~min})$ under isoflurane $(\sim 1.5 \%)$ anesthesia. The same stimulation was applied again $\sim 2 \mathrm{~h}$ later. Those mice were then returned to their home cage. This procedure was performed for three consecutive days. After the last stimulation on the third 
Table 1. Percentages of boutons formed and eliminated under various experimental conditions in adolescent ( $\sim 4-5$ weeks) and adult ( $\sim 2-4$ months) male mice

\begin{tabular}{|c|c|c|c|c|c|c|c|c|c|c|}
\hline \multirow[b]{3}{*}{ Age } & \multirow[b]{3}{*}{ Label } & \multirow[b]{3}{*}{ Treatment } & \multicolumn{3}{|c|}{ Bouton formation (\%) } & \multicolumn{3}{|c|}{ Bouton elimination (\%) } & \multirow[b]{3}{*}{ Bouton no. } & \multirow[b]{3}{*}{ Mouse no. } \\
\hline & & & \multirow[b]{2}{*}{ Mean \pm SE } & \multicolumn{2}{|c|}{$p$-value vs Ctrl } & \multirow[b]{2}{*}{ Mean \pm SE } & \multicolumn{2}{|c|}{$p$ value vs Ctrl } & & \\
\hline & & & & Parametric & Nonparametric & & Parametric & Nonparametric & & \\
\hline \multirow[t]{2}{*}{ Adolescent } & \multirow[t]{2}{*}{ TRITC-dextran } & Home cage & $1.7 \pm 0.6$ & Ctrl & Ctrl & $5.6 \pm 1.3$ & Ctrl & Ctrl & 481 & 6 \\
\hline & & Wheel running & $13.4 \pm 1.9$ & 0.001 & 0.002 & $6.9 \pm 1.0$ & 0.434 & 0.788 & 344 & 6 \\
\hline \multirow[t]{2}{*}{ Adult } & \multirow[t]{2}{*}{ TRITC-dextran } & Home cage & $1.9 \pm 1.0$ & Ctrl & Ctrl & $2.4 \pm 1.2$ & Ctrl & Ctrl & 324 & 6 \\
\hline & & Wheel running & $4.8 \pm 1.7$ & 0.16 & 0.262 & $3.2 \pm 1.4$ & 0.659 & 0.784 & 262 & 5 \\
\hline \multirow[t]{4}{*}{ Adolescent } & \multirow[t]{3}{*}{ ChR2-EYFP } & No stim & $3.0 \pm 1.6$ & Ctrl & Ctrl & $0.4 \pm 0.4$ & Ctrl & $\mathrm{Ctrl}$ & 256 & 6 \\
\hline & & Tonic stim & $3.0 \pm 1.0$ & 0.999 & 0.805 & $3.7 \pm 1.8$ & 0.132 & 0.106 & 137 & 6 \\
\hline & & Phasic stim & $19.8 \pm 4.0$ & 0.003 & 0.004 & $1.9 \pm 1.2$ & 0.287 & 0.455 & 144 & 6 \\
\hline & EGFP & Phasic stim & $3.2 \pm 0.3$ & 0.936 & 0.734 & $2.0 \pm 0.8$ & 0.107 & 0.106 & 384 & 6 \\
\hline \multirow[t]{2}{*}{ Adult } & \multirow[t]{2}{*}{ ChR2-EYFP } & No stim & $1.0 \pm 0.6$ & Ctrl & Ctrl & $3.5 \pm 1.5$ & $\mathrm{Ctrl}$ & $\mathrm{Ctrl}$ & 237 & 6 \\
\hline & & Phasic stim & $4.4 \pm 2.1$ & 0.163 & 0.318 & $0.9 \pm 0.4$ & 0.149 & 0.167 & 135 & 6 \\
\hline \multirow[t]{3}{*}{ Adolescent } & \multirow[t]{3}{*}{ ChR2-EYFP } & Saline + phasic stim & $24.4 \pm 3.8$ & Ctrl & Ctrl & $6.5 \pm 2.5$ & $\mathrm{Ctrl}$ & $\mathrm{Ctrl}$ & 235 & 6 \\
\hline & & Quinpirole + phasic stim & $5.0 \pm 1.7$ & 0.0009 & 0.002 & $2.1 \pm 0.7$ & 0.125 & 0.091 & 311 & 6 \\
\hline & & CPP/CNQX + phasic stim & $4.4 \pm 1.8$ & 0.0008 & 0.002 & $1.7 \pm 0.5$ & 0.091 & 0.041 & 202 & 6 \\
\hline \multirow[t]{3}{*}{ Adult } & \multirow[t]{3}{*}{ ChR2-EYFP } & Saline + phasic stim & $2.6 \pm 1.4$ & Ctrl & Ctrl & $1.0 \pm 0.7$ & Ctrl & $\mathrm{Ctrl}$ & 237 & 6 \\
\hline & & Eticlopride + phasic stim & $15.3 \pm 2.8$ & 0.002 & 0.002 & $1.8 \pm 0.8$ & 0.500 & 0.372 & 301 & 6 \\
\hline & & Eticlopride only & $5.2 \pm 1.6$ & 0.25 & 0.327 & $2.1 \pm 1.1$ & 0.434 & 0.437 & 311 & 6 \\
\hline
\end{tabular}

Ctrl, Control; stim, stimulation.

$p$-values relative to the age-matched control groups are shown for both parametric (Student's $t$ ) and nonparametric (Mann-Whitney) tests. The total number of boutons and total number of mice are shown for each condition. Significant $p$-values are in bold. Data are shown as means $\pm \mathrm{SE}$.

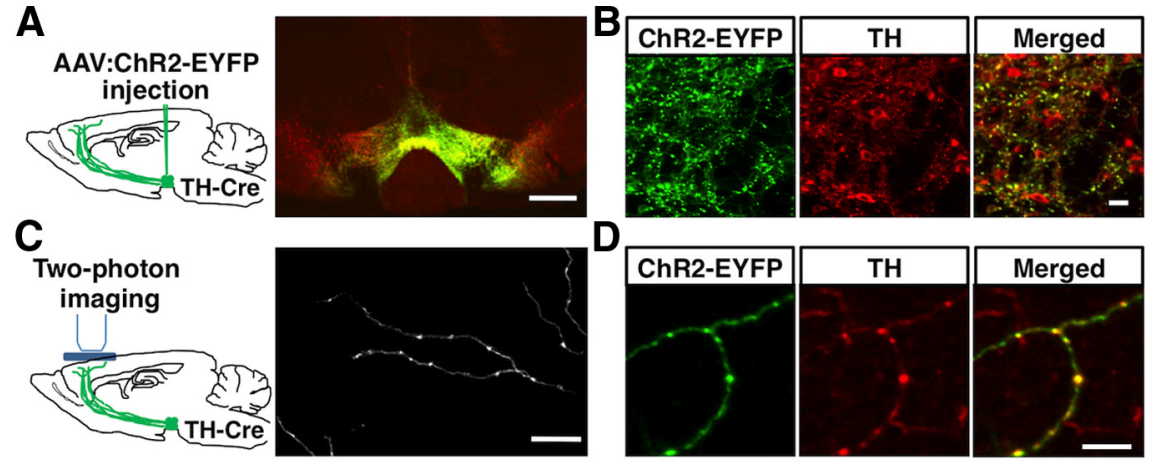

E Optical

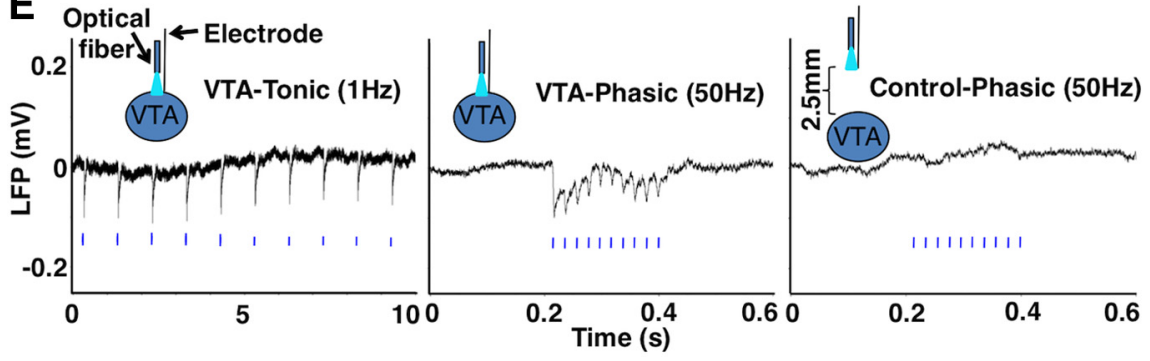

Figure 2. Optogenetic labeling and activation of dopaminergic neurons. A, B, Confocal images showing ChR2-EYFP (green) colocalized with TH-immunofluorescence (red) in the VTA of optogenetically labeled mice. ChR2-EYFP expression in dopaminergic neurons showed a high efficacy, because 90\% (109/120) of TH-immunopositive cells in the injected region expressed ChR2EYFP, and high specificity, because $~ 96 \%(109 / 113)$ of ChR2-EYFP ${ }^{+}$cells were $\mathrm{TH}^{+}$. (C) In vivo two-photon image of ChR2EYFP ${ }^{+}$axons in the FC. (D) Confocal images of FC sections showing colabeling of ChR2-EYFP (green) with TH immunofluorescence (red) in axons and boutons (repeated in 3 mice). E, LFP recordings showing VTA responses to tonic and phasic photostimulation (blue bars) in a ChR2-expressing mouse (P52). Each trace is averaged from 10 sweeps of recordings. No response was seen outside of the VTA where ChR2 was not expressed. The average number of LFP peaks ( $>3$ SDs from baseline) time locked to the 10 light pulses was $9.4 \pm 0.5(n=8$ mice) for phasic $(50 \mathrm{~Hz}), 10 \pm 0(n=4$ mice) for tonic $(1 \mathrm{~Hz})$, and $0 \pm 0$ ( $n=6$ mice) for ChR2 control $(50 \mathrm{~Hz}$ ) stimulations. Scale bars: $A, 500 \mu \mathrm{m} ; \boldsymbol{B}, \mathbf{C}, 25 \mu \mathrm{m} ; \boldsymbol{D}, 10 \mu \mathrm{m}$.

day, the animals were transferred to a new standard facility cage with food and water available ad libitum. Their behavior in this home cage was monitored using the HomeCageScan behavior monitoring system (Clever Systems) for $16 \mathrm{~h}$. Infrared lights were used for illumination during the dark cycle. Automated video analysis of home cage behaviors was performed using HomeCageScan software blind to the experimental conditions. The amount of time the animal spent in all detected active behaviors (Rear up, Walk, Eat, Drink, Hang, Turn, Stretch, Jump, Dig, Forage, Groom, Sniff) was summed.

During the light cycle one day after the last optogenetic stimulation session, the animals were placed in an open field arena $(50 \mathrm{~cm} \times 50$ $\mathrm{cm} \times 10 \mathrm{~cm})$ for $10 \mathrm{~min}$, then received D-amphetamine (2 mg/kg, i.p.) injection, and monitored by video camera for another $60 \mathrm{~min}$ in the arena. The animal's body position was automatically tracked and analyzed using the Limelight video tracking system (ActimetricsCoulbourn Instruments) with the investigator blinded to the experimental conditions. The total distance traveled in 5 min bins of time was calculated from the tracked body positions. The percentage of time the animal spent in the center $(30 \times 30 \mathrm{~cm})$ of the arena was determined from the position data. Rearing behavior was analyzed in the video by a human observer blinded to the experimental conditions. Starting at the $10^{\text {th }}$ minute after amphetamine injection, the first minute of every $10 \mathrm{~min}$ of video was inspected visually. The number of rears that mice displayed during this time window was counted and these counts were summed for each animal.

c-Fos expression in the FC and NA after amphetamine treatment. After the $60 \mathrm{~min}$ amphetamine test, the animals were perfused and c-Fos immunostaining in the FC and NA was performed. Two coronal sections (1.6 and $1.2 \mathrm{~mm}$ anterior from bregma) were imaged using a $10 \times$ lens. Regions of interest covering the FC and NA were drawn in the images according to the stereotaxic atlas (Paxinos and Franklin, 2004) with the investigator blinded with regard to experimental conditions. The total areas of the regions of interest are as follows: FC (M2, Cg, PrL, IL) = $5.05 \mathrm{~mm}^{2}$, NA (core and shell) $=3.80 \mathrm{~mm}^{2}$. Cell nuclei within these regions of interest were detected automatically by thresholding the images at 3 SDs above background and then selecting particles $49-$ $200 \mu \mathrm{m}^{2}$ in size using ImageJ. 
Statistical analysis. No statistical methods were used to predetermine sample sizes, but our sample sizes are similar to those reported previously (Flores et al., 2005; Lavin et al., 2005; De Paola et al., 2006; Nishiyama et al., 2007). All data are expressed as the mean \pm SE. Statistical differences between two groups were determined with two-sided Student's $t$ test or Mann-Whitney test. Statistical differences among three groups or more were determined using one-way ANOVA, two-way ANOVA, or repeated-measures (RM) ANOVA, followed by Bonferroni's multiplecomparisons test. We found no major deviation from the assumptions of the ANOVA. For the cases in which normality or equal variance was questionable, the results of the ANOVA were confirmed by nonparametric tests (Kruskal-Wallis followed by post hoc Dunn's test).

\section{Results}

Wheel running enhances the formation of mesofrontal boutons in adolescent mice

Seeking to investigate activity-dependent modification of the mesofrontal circuit, we first conducted an exploratory experiment to examine potential changes in the mesofrontal axons in response to wheel-running behavior, which increases phasic dopamine neuron activity in the VTA (Wang and Tsien, 2011). We used in vivo two-photon microscopy to examine mesofrontal axons because this method can determine structural changes in the same axons before and after experimental manipulation. With this method, changes in axonal boutons are typically measured in proportion to the number of boutons sampled before experimental manipulation; bouton formation or elimination rates ranging from a few percentages at baseline level to tens of percentages hours after activity perturbation have been reported on cortical glutamatergic or GABAergic axons (Holtmaat et al., 2009; Fu and Zuo, 2011). However, the dynamics of mesofrontal axonal boutons have yet to be examined.

To label mesofrontal axons for imaging, we injected a fluorescent tracer, dextran-coupled TRITC, into the VTA (Fig. 1A-D). $\mathrm{TH}$ immunostaining of the FC (M2 region, layers I-III) revealed that $63 \pm 4 \%$ of TRITC-labeled axons were TH-positive, and the rest might have been nondopaminergic axons originating from the VTA (Fields et al., 2007). We examined in vivo changes of TRITC-labeled boutons in response to $2 \mathrm{~h}$ of wheel running or home cage activities in adolescent $(\sim 4-5$ weeks $)$ and adult ( $\sim 2-4$ months) male mice. The proportion of newly formed boutons increased after wheel running in adolescence (from $1.7 \pm 0.6 \%$ to $13.4 \pm 1.9 \%)$ and this effect diminished in adulthood (from $1.9 \pm 1.0 \%$ to $4.8 \pm 1.7 \%$; two-way ANOVA age-bycondition interaction, $\left.\left.F_{(1,19}\right)=9.89, p<0.005\right)$. By contrast, there was no significant difference in the elimination of boutons (two-way ANOVA age-by-condition interaction, $F_{(1,19)}=0.04$, $p=0.842$; Fig. $1 E, F$, Table 1$)$. Although wheel running is a complex behavioral treatment that does not specifically target dopamine neurons, these observations raise the possibility that, in adolescent mice, increasing phasic dopamine neuron activity may enhance the formation of mesofrontal boutons and that, in adult mice, this activity perturbation may be less effective.

Optogenetic labeling and activation of dopaminergic neurons To investigate directly whether dopamine neuron activity affects the structure and function of the mesofrontal circuit, we adopted an optogenetic method to selectively label and activate dopaminergic neurons. We injected an AAV carrying a Cre recombinasedependent expression construct for channelrhodopsin-2 fused with enhanced yellow fluorescent protein (ChR2-EYFP; Tsai et al., 2009) into the VTA of transgenic mice that expressed Cre under the control of TH promoter (Gong et al., 2007; Fig. 2A,B). ChR2-EYFP-labeled axons were detectable by in vivo two-photon
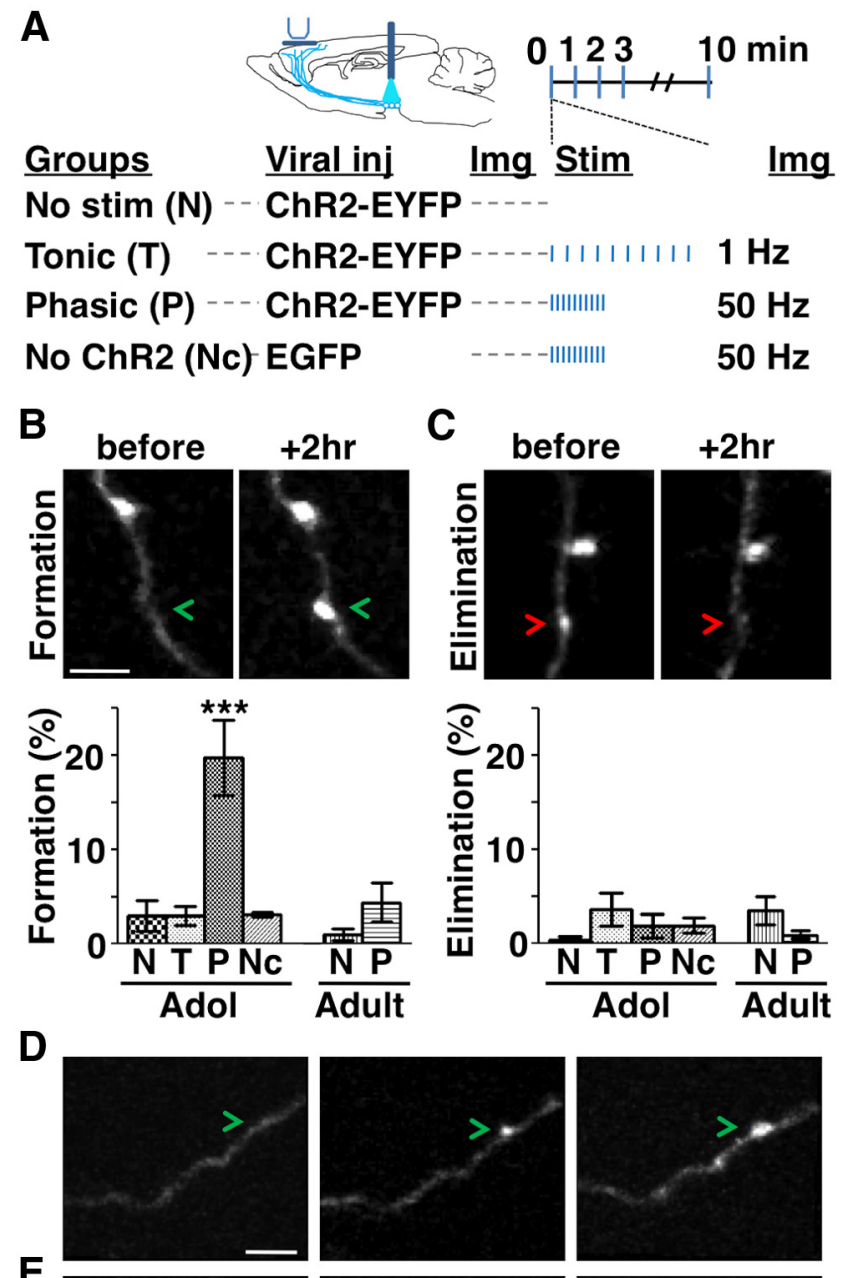

.
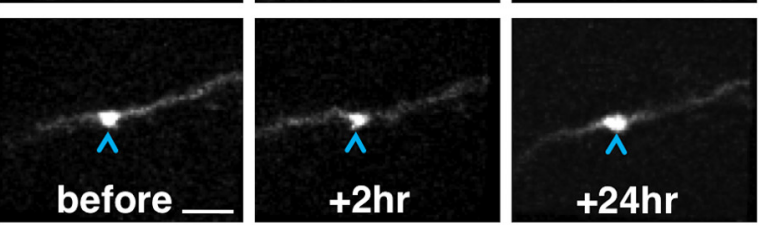

Figure 3. Phasic activation promotes mesofrontal bouton formation in adolescence. $\boldsymbol{A}, \mathrm{Ex}$ perimental conditions. $\boldsymbol{B}, \boldsymbol{C}$, Top, two-photon images showing bouton formation ( $\boldsymbol{B}$, arrowheads) and elimination ( $\boldsymbol{C}$, arrowheads) on mesofrontal axons over a $2 \mathrm{~h}$ interval. Bottom, Percentage of boutons formed $(\boldsymbol{B})$ and eliminated $(\boldsymbol{C})$ in adolescent $(\sim 4-5$ weeks) and adult $\left(\sim 2-4\right.$ months) male mice. For $\boldsymbol{B}$, one-way ANOVA $F_{(5,30)}=12.09, p<0.0001$; Bonferroni's posttest, ${ }^{* * *} p<0.001$, adolescent phasic group versus all other groups. For $\boldsymbol{C}$, one-way ANOVA $F_{(5,30)}=1.33, p=0.279 . n=6$ mice each group. Data are means \pm SE. $\boldsymbol{D}, \boldsymbol{E}$, Two-photon images showing newly formed ( $\boldsymbol{D}$, arrowheads) and preexisting ( $\boldsymbol{E}$, arrowheads) boutons identified $2 \mathrm{~h}$ after phasic stimulation persisted after $24 \mathrm{~h}$ in adolescent mice (repeated in 9 mice). The majority $(79 \%, 19 / 24)$ of new axonal boutons formed $2 \mathrm{~h}$ after phasic stimulation were still present $24 \mathrm{~h}$ later, comparable to the stability of boutons that existed before stimulation (88\%, $109 / 124 ; p=0.75, \chi^{2}$ test). Scale bars, $5 \mu \mathrm{m}$.

microscopy in the FC (M2 region, layers I-III; Fig. 2C) and those axons and boutons were colabeled with $\mathrm{TH}$ immunofluorescence in brain sections (Fig. 2D).

To activate dopaminergic neurons, we inserted an optic fiber over the VTA in ChR2-EYFP-expressing mice (Fig. 2E) and applied tonic $(1 \mathrm{~Hz})$ or phasic $(50 \mathrm{~Hz})$ blue light pulse trains (10 pulses/train) mimicking the natural activity patterns of those neurons (Grace et al., 2007; Tsai et al., 2009). To verify neuronal responses to light stimulation, we conducted local field potential (LFP) recordings, which sample the average activity of neurons locally (Lewis and O’Donnell, 2000; Lavin et al., 2005). We observed robust LFP re- 

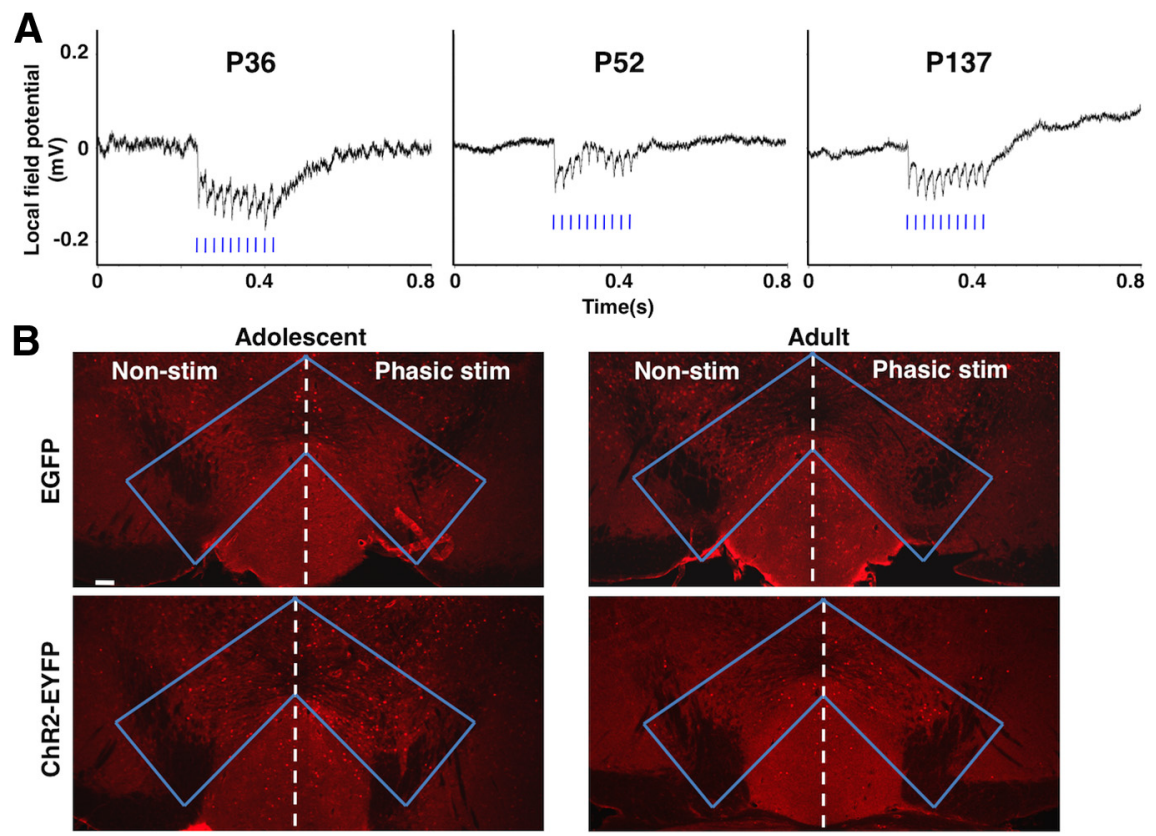

C

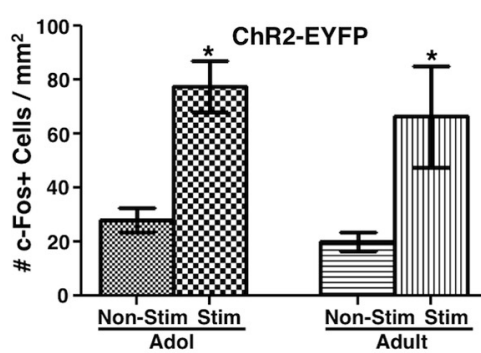

E

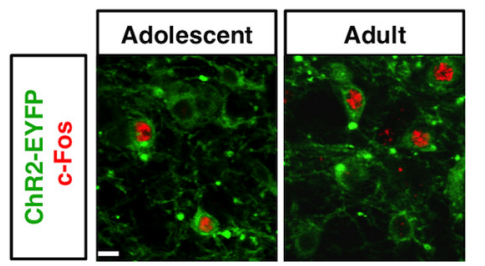

D

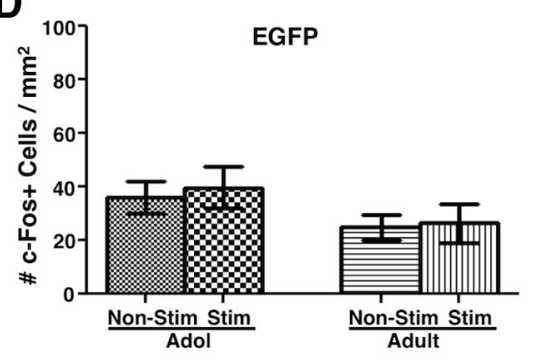

$\mathbf{F}$

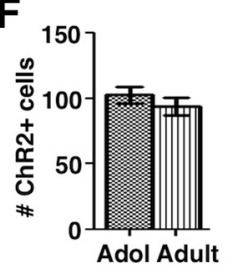

G

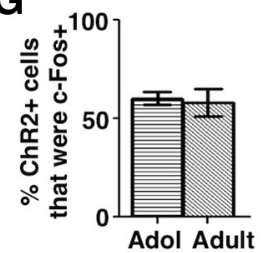

Figure 4. Phasic activation induces robust LFP response and comparable c-Fos expression in adolescent and adult mice. $A$, VTA LFP traces in response to phasic light stimulation of ChR2-expressing dopamine neurons in mice with ages ranging from adolescence to adulthood. $50 \mathrm{~Hz}$ LFP responses time locked to $50 \mathrm{~Hz}$ phasic light pulses (blue bars) were observed in all ages. Average of 10 sweeps of LFP recordings are shown for each condition. $\boldsymbol{B}$, Confocal images of c-Fos immunofluorescence in the VTA of adolescent $(\sim 4-5$ weeks) and adult ( $\sim 2-4$ months) mice that were transduced with either AAV:ChR2-EYFP or AAV:EGFP and unilaterally stimulated with phasic light pulses. C, In AAV:ChR2-EYFP-transduced mice, the density of c-Fos ${ }^{+}$cells at the stimulated side was increased to a similar extent between adolescent ( $\sim 4-5$ weeks) and adult ( $~ 2-4$ months) mice. RM-ANOVA: stimulation, $F_{(1,6)}=27.80, p=0.002$; age, $F_{(1,6)}=0.585, p=$ 0.474 ; simulation-by-age interaction, $F_{(1,6)}=0.034, p=0.859$; nonstimulated versus stimulated, adolescent ${ }^{*} p=0.017$, adult ${ }^{*} p=$ 0.023 , Bonferroni's posttests, $n=4$ mice for each group. $D$, In AAV:GFP-transduced mice, no significant difference was observed. RMANOVA: stimulation, $F_{(1,6)}=0.990, p=0.358$; age, $F_{(1,6)}=1.91, p=0.216$; interaction, $F_{(1,6)}=0.196, p=0.674 . n=4$ mice for each group. $\boldsymbol{E}$, Confocal images of ChR2-EYFP (green) and c-Fos (red) labeled cells in the VTA of adolescent and adult mice after phasic stimulation. $\boldsymbol{F}, \mathbf{G}$, The number of ChR2 ${ }^{+}$cells $(\boldsymbol{F})$ in $636 \times 636 \times 12 \mu \mathrm{m}^{3}$ image stacks from two sections/mouse and the percentage of ChR2 ${ }^{+}$ cells that were $c-F_{0 s}{ }^{+}(\boldsymbol{G})$ are not different between adolescent and adult mice. $p=0.390(\boldsymbol{F})$ and $0.789(\boldsymbol{G}), t$ tests, $n=4$ mice each. Scale bars: $\boldsymbol{B}, 100 \mu \mathrm{m} ; \boldsymbol{E}, 10 \mu \mathrm{m}$. Data are means $\pm \mathrm{SE}$.

sponses to both tonic and phasic stimulation in the VTA and no response outside of the VTA in the absence of ChR2 expression (Fig. $2 E$ ). These results confirmed the specific activation of ChR2expressing dopamine neurons by light.

Phasic activation of dopamine neurons promotes mesofrontal bouton formation in adolescence

To determine the effect of VTA activation on mesofrontal innervation, we imaged ChR2-EYFP-labeled dopaminergic axons by two-photon microscopy in the FC before and $2 \mathrm{~h}$ after VTA activation. We used near infrared laser $(920 \mathrm{~nm})$ to excite YFP under two-photon mechanism. ChR2 activation normally occurs under onephoton illumination by blue light (470 $\mathrm{nm})$. Although ChR2 could in principle conduct a small amount of photocurrent in response to two-photon illumination by near infrared laser, previous studies using standard laser-scanning two-photon microscopy did not find evidence of neural activation, and this was attributed to limits in laser power, focal volume, and scanning duration (Zhang and Oertner, 2007; Rickgauer and Tank, 2009; Andrasfalvy et al., 2010; Papagiakoumou et al., 2010).

To control for any potential effect that might be contributed by two-photon imaging of ChR2-EYFP-labeled axons in our study, we included three groups of mice that all underwent the same extent of twophoton imaging in the $\mathrm{FC}$, but received no stimulation, tonic $(1 \mathrm{~Hz})$ stimulation, or phasic $(50 \mathrm{~Hz})$ stimulation to the VTA (Fig. $3 A$ ). In addition, to control for any potential effect related to the phasic light itself, we transduced another group of mice with an EGFP-encoding AAV that produces no ChR2 expression and subjected these mice to the same phasic light stimulation and imaging procedures.

We found that, in adolescent $(\sim 4-5$ weeks) male mice, the proportion of newly formed boutons increased in response to phasic, but not tonic, stimulation and this effect only occurred when ChR2 was expressed (no stimulation: $3.0 \pm 1.6 \%$, tonic stimulation: $3.0 \pm$ $1.0 \%$, phasic stimulation: $19.8 \pm 4.0 \%$, no ChR2: $3.2 \pm 0.3 \%$; one-way ANOVA, $F_{(5,30)}=12.09, p<0.0001 ;$ Bonferroni's posttests, only phasic stimulation differs from the other groups, $p<0.001$; Fig. $3 B$, Table 1). Bouton elimination was not different among those groups (one-way ANOVA $F_{(5,30)}=1.33, p=0.279$; Fig. $3 C$, Table 1). Because the same two-photon imaging procedure was applied to all the groups, the effect of phasic stimulation on bouton formation cannot be attributed to the two-photon laser. In addition, ChR2negative axons exhibited similar bouton dynamics as ChR2-positive axons that received no VTA stimulation, further indicating that imaging ChR2-labeled axons with twophoton laser did not affect bouton dynamics. Together, these results suggest that phasic, but not tonic, activation of dopaminergic neurons is sufficient to induce mesofrontal bouton formation in adolescent mice.

Next, we investigated whether the axonal boutons formed after phasic activation would persist in the adolescent FC beyond the $2 \mathrm{~h}$ period thus far examined. We imaged mesofrontal axons 
before and $2 \mathrm{~h}$ after phasic stimulation; the imaged mice were then returned to their home cages and imaged again $24 \mathrm{~h}$ later. The majority $(79 \%, 19 / 24)$ of new axonal boutons formed $2 \mathrm{~h}$ after phasic stimulation were still present $24 \mathrm{~h}$ later, comparable to the stability of boutons that existed before stimulation $(88 \%$, $109 / 124 ; p=0.75, \chi^{2}$ test; Fig. $\left.3 D, E\right)$. Therefore, phasic activation of dopaminergic neurons induced the formation of stable mesofrontal boutons in adolescent mice.

\section{Effect of phasic activity on mesofrontal boutons diminishes in adulthood}

To examine the effect of phasic activation on adult $(\sim 2-4$ months) mesofrontal axons, we applied the same phasic stimulation and imaging procedures. Several lines of evidence suggest that the imaging and stimulation conditions are comparable between adolescent and adult mice. First, at the gross anatomical level, there is little difference between adolescent and adult rodents in the midbrain and the frontal cortical regions (Kalsbeek et al., 1988; also see Figs. 4B, 8A). In our study, axonal boutons were sampled in the same cortical region and layers (M2, layers I-III) and bouton dynamics were measured as a percentage of preexisting structures similar to other two-photon imaging studies comparing different age groups (Holtmaat et al., 2009; Fu and Zuo, 2011). Second, we found that $50 \mathrm{~Hz}$ LFPs were evoked reliably by $50 \mathrm{~Hz}$ light stimulation in the VTA from adolescence to adulthood (Fig. 4A). Third, ChR2-EYFP expression was comparable between adolescent and adult VTA ( $p=0.390, t$ test; Fig. $4 E, F)$. Fourth, the numbers of VTA cells activated by phasic stimulation (RM-ANOVA: stimulation, $F_{(1,6)}=27.80, p=0.002$; age, $F_{(1,6)}=$ $0.585, p=0.474$; stimulation-by-age interaction, $F_{(1,6)}=0.034$, $p=0.859$; Fig. $4 B-D)$, as indicated by the induction of immediate-early gene $c$-Fos (Tye and Deisseroth, 2012), and the percentages of ChR2 ${ }^{+}$cells that were $c-F o s{ }^{+}(p=0.789, t$ test; Fig. $4 E, G)$, were similar between adolescent and adult mice.

In adult mice, however, phasic activation did not lead to any significant change of bouton dynamics compared with the nostimulation group (Fig. 3 B, C, Table 1). The proportion of newly formed boutons in the stimulated mice was less in adulthood $(4.4 \pm 2.1 \%)$ than that in adolescence $(19.8 \pm 4.0 \%, p=0.004$, Bonferroni's posttest; two-way ANOVA age-by-stimulation interaction, $\left.F_{(1,20)}=7.8, p=0.011\right)$. Therefore, phasic VTA activation has less effect on mesofrontal boutons in adult mice than in adolescent mice.

\section{D2R signaling regulates bidirectionally the axonal plasticity induced by phasic activity}

We next investigated what neurotransmitter may regulate phasic activity-induced bouton formation. In response to activation, dopamine and glutamate can be coreleased from VTA dopamine neurons (Sulzer et al., 1998; Lavin et al., 2005; Stuber et al., 2010), which might affect the structural plasticity of dopaminergic axons. Glutamatergic transmission through NMDA- and AMPAtype receptors has been implicated in the plasticity of excitatory synapses (McAllister, 2007; Fu and Zuo, 2011). For dopaminergic axons, it has been reported that genetic ablation of dopamine D2 receptor (D2R), but not D1 receptor (D1R), affects axonal structures. Consistent with the effects of genetic ablation, long-term pharmacological treatment with $\mathrm{D} 2 \mathrm{R}$ antagonists resulted in sprouting of dopaminergic axons, whereas treatment with D2R agonists led to pruning of axon arbors in the striatum (Parish et al., 2001; Parish et al., 2002). Whether glutamatergic and D2R signaling regulates the plasticity of mesofrontal dopaminergic boutons, however, remains unknown.
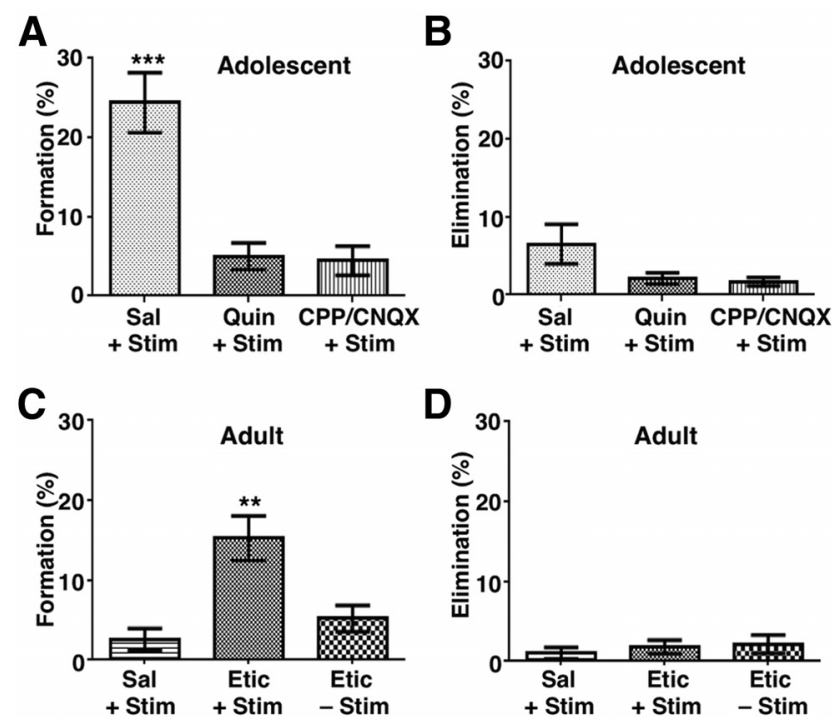

Figure 5. D2R signaling regulates bidirectionally the axonal plasticity induced by phasic activity. $\boldsymbol{A}, \mathrm{D} 2 \mathrm{R}$ agonist quinpirole (Quin, $1 \mathrm{mg} / \mathrm{kg}$, i.p.) significantly suppresses phasic activation-induced bouton formation in adolescent mice. The NMDAR antagonist CPP $(3 \mathrm{mg} / \mathrm{kg})$ plus the AMPAR antagonist CNQX (10 mg/kg, i.p.) also led to significant suppression. One-way ANOVA $F_{(2,15)}=18.77, p<0.0001$; Bonferroni's posttest, ${ }^{* * *} p<0.001$, saline $($ Sal $)+$ stimulation (Stim) group versus all other groups. $\boldsymbol{B}$, No significant difference is observed in the elimination of boutons in adolescent mice. One-way ANOVA $F_{(2,15)}=2.98, p=0.081$. $\boldsymbol{C}$, Although treatment with the D2R antagonist eticlopride (Etic, $0.5 \mathrm{mg} / \mathrm{kg}$, i.p.) without phasic stimulation did not affect bouton formation, eticlopride treatment did enhance bouton formation in response to phasic stimulation in adult mice. One-way ANOVA, $F_{(2,15)}=10.84, p=$ 0.0012 ; Bonferroni's posttest, ${ }^{* *} p<0.01$, Etic + Stim group versus all other groups. $\boldsymbol{D}$, No significant difference is observed in the elimination of boutons in adult mice. One-way ANOVA $F_{(2,15)}=0.380, p=0.691 . n=6$ mice each group. Data are means $\pm S E$.

We first tested whether acute pharmacological modulation of dopaminergic and glutamatergic transmission could block the increased bouton formation induced by phasic activity in adolescent mice. To avoid mechanical disruption of axonal structures potentially resulting from drug infusion into the FC, we administered pharmacological reagents by intraperitoneal injection minutes before phasic stimulation. We found that, in adolescent mice, D2R agonist (quinpirole, $1 \mathrm{mg} / \mathrm{kg}$ ) or glutamate receptor antagonists (CPP for NMDA-type receptors, $3 \mathrm{mg} / \mathrm{kg}$, administered together with CNQX for AMPA-type receptors, $10 \mathrm{mg} / \mathrm{kg}$ ) suppressed the bouton formation induced by phasic stimulation (saline + stimulation: $24.4 \pm 3.8 \%$, quinpirole + stimulation: $5.0 \pm 1.7 \%, \mathrm{CPP} / \mathrm{CNQX}+$ stimulation: $4.4 \pm 1.8 \%$; one-way ANOVA, $F_{(2,15)}=18.77, p<0.0001$; Bonferroni's posttests, $p<$ 0.001 , saline + stimulation vs all other groups; Fig. $5 A, B$, Table $1)$. These results suggest that both dopaminergic and glutamatergic signaling regulate the structural changes induced by phasic activity in adolescence.

The suppressive effect of D2R activation on bouton formation raises the possibility that inhibiting $\mathrm{D} 2 \mathrm{R}$ activity might restore the structural plasticity of mesofrontal axons in adult mice. Indeed, we found that whereas treatment with the D2R antagonist eticlopride $(0.5 \mathrm{mg} / \mathrm{kg}$, i.p. $)$ alone without phasic stimulation did not affect bouton formation, eticlopride treatment did enhance bouton formation in response to phasic stimulation in adult mice (saline + stimulation: $2.6 \pm 1.4 \%$, eticlopride + stimulation: $15.3 \pm 2.8 \%$, eticlopride + no stimulation: $5.2 \pm 1.6 \%$; one-way ANOVA, $F_{(2,15)}=10.84, p=0.0012$; Bonferroni's posttest, $p<$ 0.01 , eticlopride + stimulation group vs all other groups; Fig. $5 C, D$, Table 1$)$. Together, our results suggest that $\mathrm{D} 2 \mathrm{R}$ signaling 
A

B
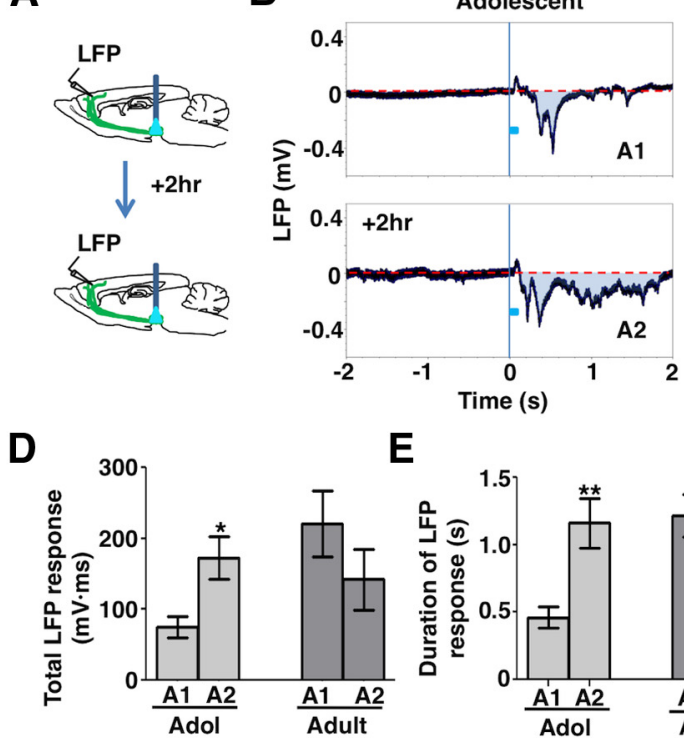

E

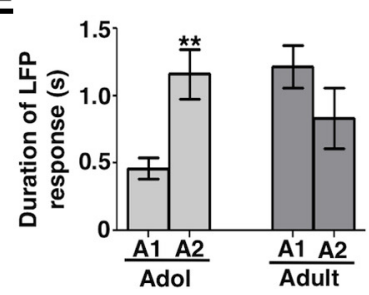

G

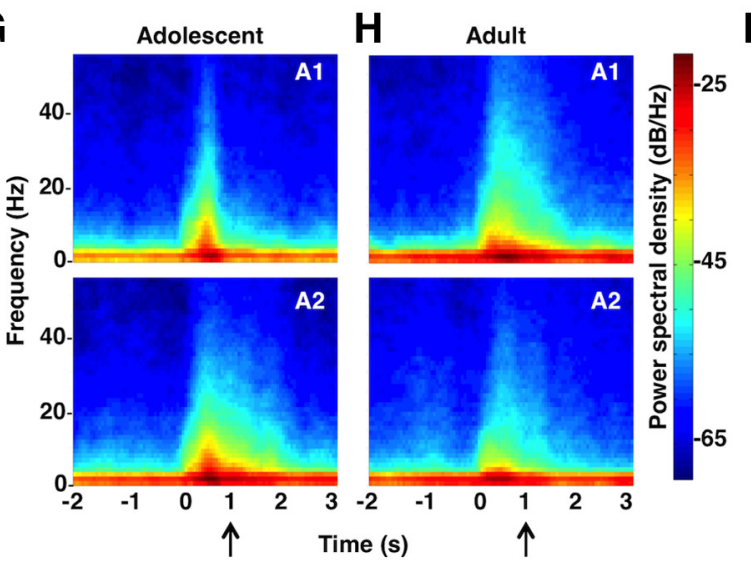

C

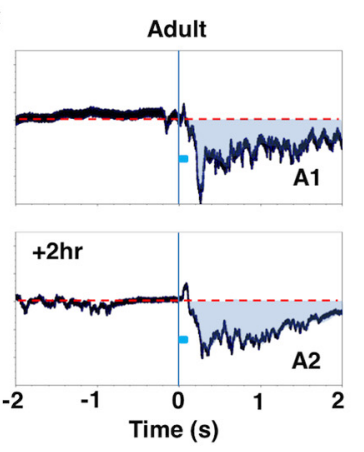

$\mathbf{F}$

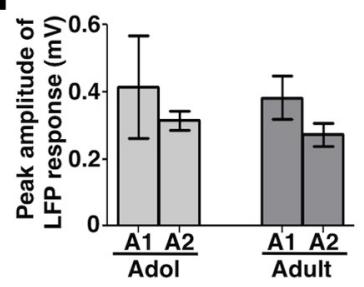

I

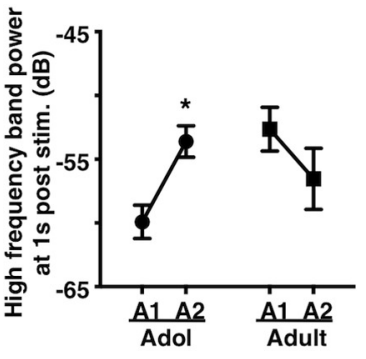

Figure 6. Phasic activation leads to elevated mesofrontal circuit activity in adolescence. $\boldsymbol{A}$, Experimental conditions. $\boldsymbol{B}, \boldsymbol{C}$, Frontal cortical LFPs evoked by phasic VTA activation in an adolescent $(\boldsymbol{B})$ and adult $(\boldsymbol{C})$ mouse. The blue boxes indicate phasic stimuli $(50 \mathrm{~Hz}$ pulses for $200 \mathrm{~ms}$ ). The shaded areas $(A 1, A 2)$ indicate total LFP responses induced by VTA stimulation. Each trace is averaged from 10 sweeps of recordings. D, Total LFP responses in session 1 (A1) and 2 (A2) in adolescent ( $\sim 4-5$ weeks) and adult ( $\sim 2-4$ months) mice. Two-way RM-ANOVA, age-by-session interaction, $F_{(1,14)}=13.82, p=0.002$; Bonferroni's posttest, adolescent (Adol) $A 1$ versus $A 2,{ }^{*} p=0.023$. $E$, Duration of LFP responses in session 1 (A1) and 2 (A2) in adolescent and adult mice. RM-ANOVA, age-by-session interaction, $F_{(1,14)}=19.4, p=0.0006$. Bonferroni's posttest, Adol A1 versus $A 2,{ }^{* *} p=0.003 . \boldsymbol{F}$, Peak amplitude of LFP responses in session 1 (A1) and 2 (A2) in adolescent and adult mice. No significant difference was observed in adolescent or adult mice. RM-ANOVA: age, $F_{(1,14)}=0.146, p=0.708$; session, $F_{(1,14)}=1.983, p=0.181$; interaction, $F_{(1,14)}=$ $0.004, p=0.948$. $\mathbf{G}, \boldsymbol{H}$, Spectrogram of the LFP signals in a period from $2 \mathrm{~s}$ before VTA stimulation to $3 \mathrm{~s}$ after in adolescent $(\boldsymbol{G})$ and $\operatorname{adult}(\boldsymbol{H})$ mice. Spectral analyses were conducted for each $0.5 \mathrm{~s}$ sliding window $(0.1 \mathrm{~s}$ step) in individual sweeps of $L F P$ recordings. The graphs show the average of all the animals in each condition. $I$, To summarize the long-lasting changes in high-frequency oscillations, the power spectral density calculated at $1 \mathrm{~s}$ post VTA stimulation (arrows in $\boldsymbol{G}$ and $\boldsymbol{H}$ ) was averaged over a highfrequency band ( $4-55 \mathrm{~Hz}, \theta$ to $\gamma$ oscillation range) for each subject and condition. RM-ANOVA, age-by-session interaction, $F_{(1,14)}$ $=11.83, p=0.004$; Bonferroni's posttest, Adol A1 versus A2, ${ }^{*} p=0.019 . n=8$ mice for each group. Data are means $\pm S E$.

regulates bidirectionally the axonal plasticity induced by phasic activity.

\section{Phasic activation of dopamine neurons led to elevated} mesofrontal circuit activity in adolescence

Because phasic activation of VTA neurons altered the structure of adolescent mesofrontal circuit, we investigated whether this activation would also lead to functional changes consistent with the observed structural changes. Previous studies showed that phasic electrical stimulation of VTA evoked sustained neural activity outlasting the stimulus by more than hundreds of milliseconds in the adult FC. This prolonged activity depends on dopaminergic signaling and reflects enhanced local circuit activity in the presence of dopaminergic activation (Lewis and O'Donnell, 2000; Lavin et al., 2005; Onn and Wang, 2005). However, it is not yet known whether this functional characteristic of the mesofrontal circuit would be modified by the prior occurrence of phasic activity in dopamine neurons.

To address this question, we compared frontal cortical LFP responses (M2 region, layer II/III) to phasic optical stimulation of VTA between two recording sessions separated by a $2 \mathrm{~h}$ interval, as in our imaging experiments (Fig. 6A). We used LFP recording because it provides a robust index of the population activity in local neurons (Buzsáki et al., 2012). This method has been used to reveal the sustained frontal activity evoked by VTA stimulation (Lewis and O'Donnell, 2000; Seamans et al., 2003; Lavin et al., 2005) and highfrequency cortical oscillations (from $\theta$ to $\gamma$ range) that are modulated by dopaminergic signaling (Costa et al., 2006; Gireesh and Plenz, 2008; Wood et al., 2012; Furth et al., 2013).

Previous studies have shown that the shift of LFP trace below the prestimulation baseline indicates excitatory response to VTA activation (Lewis and O'Donnell, 2000; Seamans et al., 2003; Lavin et al., 2005). Using this measure, we found an enhanced total LFP response in the second session compared with the first session in adolescent mice, but not in adult mice (RM-ANOVA, age-by-session interaction, $F_{(1,14)}=13.82$, $p=0.002$; Bonferroni's posttest, adolescent session 1 vs 2 , $p=0.023$; Fig. $6 B-D)$. Rather than changes in peak amplitude (RM-ANOVA, age-by-session interaction, $F_{(1,14)}=$ $0.004, p=0.948$; Fig. $6 F)$, this enhanced total LFP response was associated with an increase in response duration (RMANOVA, age-by-session interaction, $F_{(1,14)}=19.4, p=0.0006$; Bonferroni's posttest, adolescent session 1 vs $2, p=$ 0.003; Fig. 6E).

To further examine the potential changes in high-frequency cortical oscillations, we analyzed the spectrogram of LFP signals around the time of VTA stimulation in each session (Fig. 6G,H). The spectrogram shows the distribution of signal power over frequency range in each short segment $(0.5 \mathrm{~s})$ of LFP signals. We found that, nested on top of the slow responses, phasic VTA stimulation also evoked higher frequency responses ranging from $\theta$ to $\gamma(4-55$ $\mathrm{Hz}$ ) oscillations. Moreover, comparing the second session with the first session, phasic stimulation led to more prolonged increase of high-frequency power in adolescent mice, but not in adult mice (RM-ANOVA, age-by-session interaction, $F_{(1,14)}=$ 11.83, $p=0.004$; Bonferroni's posttest, adolescent session 1 vs 2 , $p=0.019$; Fig. $6 I$ ). 
Those changes in higher-frequency oscillations are consistent with what we observed in the slow shift of LFP response. Together, those findings indicate that phasic VTA activation potentiates mesofrontal circuit activity in adolescents, which is associated with enhanced dopaminergic input. Moreover, our results suggest that phasic activity can elicit lasting changes in both the structure and function of the mesofrontal circuit in adolescents and that these changes occur in an age-dependent manner.

Phasic VTA activation led to suppressed psychomotor activity in adolescence The greater impact of phasic activity on the adolescent mesofrontal circuit raises the possibility that behaviors regulated by this circuit could be more readily altered in adolescent mice than in adult mice. Locomotor activity induced by exposure to novel environments or amphetamine is sensitive to frontal dopaminergic input (Tzschentke, 2001; Chambers et al., 2003). For example, increase of mesofrontal dopamine inputs by pharmacological or genetic manipulation is associated with suppression of psychomotor activity (Tzschentke, 2001; Flores et al., 2005; Niwa et al., 2013). Because phasic VTA stimulation promoted mesofrontal innervation more effectively in adolescent mice than in adult mice, we investigated whether this stimulation would also lead to suppressed psychomotor activity in adolescents, but not adults.

To evaluate the long-lasting effects of phasic VTA activation on psychomotor behavior, we delivered phasic light patterns twice per day for $3 \mathrm{~d}$ to adolescent $(\sim 4-5$ weeks $)$ and adult ( $\sim 2-4$ months) mice transduced with EGFP- or ChR2-encoding virus. After the last stimulation, those mice were videomonitored in their home cages for $\sim 16 \mathrm{~h}$, exposed to a novel open-field arena, and received amphetamine injection $(2 \mathrm{mg} / \mathrm{kg})$ to test psychomotor activity (Fig. $7 A$ ).

All groups of mice spent similar time in spontaneously active behaviors in their home cages (one-way ANOVA, $F_{(3,20)}=1.21$, $p=0.332$; Fig. $7 B$ ). However, their activities differed under the psychomotor test (Fig. $7 C, D)$. During the initial exposure to the novel test chamber, the stimulated adolescent mice traveled less than the control adolescent mice (Kruskal-Wallis test, $p=0.032$; Dunn's posttest, $p=0.007$; Fig. $7 C$ ). After amphetamine injection, the locomotor activity of the stimulated adolescent mice was also consistently reduced compared with that of the control adolescent mice (Kruskal-Wallis test, $p=0.005$; Dunn's posttest, $p=0.008$; Fig. $7 D$ ). This reduction in locomotion was not associated with an increase in stereotypic rearing behavior or avoidance of arena center (Fig. 7E,F). Therefore, these findings suggest that psychomotor response was suppressed in adolescent mice that received prior phasic stimulation compared with those that received no stimulation. In contrast, the same stimulation did not alter the locomotor activity in adult mice (Fig. $7 C, D$ ), suggesting that psychomotor activity in adult mice is less sensitive to the suppressive effect of prior phasic VTA stimulation.

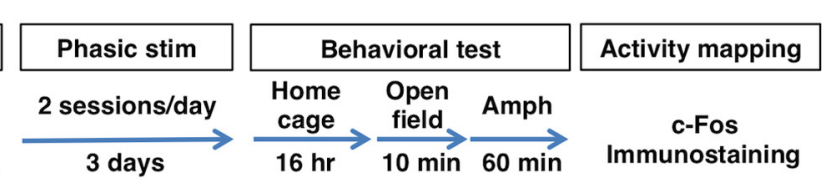

C

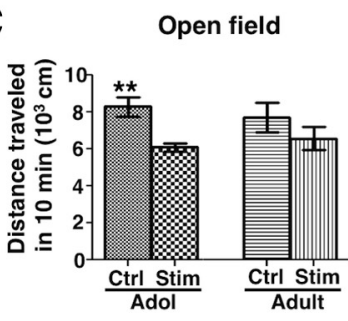

D

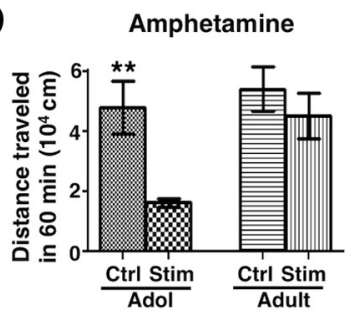

$\mathbf{F}$

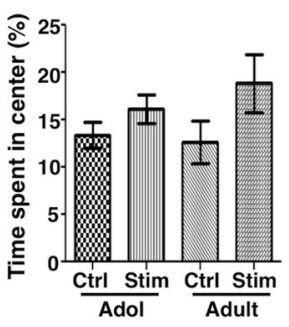

Figure 7. Phasic VTA activation led to suppressed psychomotor activity in adolescence. $A$, Experimental conditions. $B$, Duration 作 Adult-Ctrl, for which $n=10$. $F$, The percentage of time spent in the center of open field is not significantly different between the groups (one-way ANOVA, $F_{(3,33)}=1.73, p=0.181, n=9$ mice each, except Adult-Ctrl, for which $n=10$ ). Data are means $\pm S E$.

Phasic VTA activation led to enhanced c-Fos expression in FC versus NA in adolescence

Previous studies have suggested competing roles of the FC and the NA in regulating psychomotor response. Although activation of NA and its associated dopaminergic input facilitates psychomotor response, activation of the mesofrontal circuit exerts an inhibitory effect on this response (Le Moal and Simon, 1991; Tzschentke, 2001; Chambers et al., 2003). To ascertain whether the suppression of psychomotor activity induced by phasic VTA stimulation is most consistent with activity changes in the FC, in the NA, or both, we performed c-Fos immunostaining in these two regions after the behavioral tests. Compared with the EGFP control group, c-Fos expression was increased in the FC, but not in the NA, of ChR2-stimulated adolescent mice (Fig. 8A, B), suggesting that the suppression of psychomotor activity induced by phasic VTA stimulation is more consistent with neural plasticity in the mesofrontal circuit than with that in the mesoaccumbens circuit. The increase of the FC-to-NA activation ratio due to VTA stimulation occurred only in adolescence, but not in adulthood ( $p=0.0003$, Bonferroni's posttest; ANOVA age-by-stimulation interaction, $F_{(1,28)}=7.1, p=0.013$; Fig. $\left.8 C\right)$, suggesting again that the adult mesofrontal circuit is less sensitive to the effects of prior phasic VTA stimulation.

\section{Discussion}

Here, we report that phasic dopamine neuron activity induces unique plasticity of the mesofrontal dopaminergic circuit in adolescence. Using optogenetic methods to control the activity of dopamine neurons directly, we found that, in adolescent mice, phasic activation of dopamine neurons elicits lasting changes in 


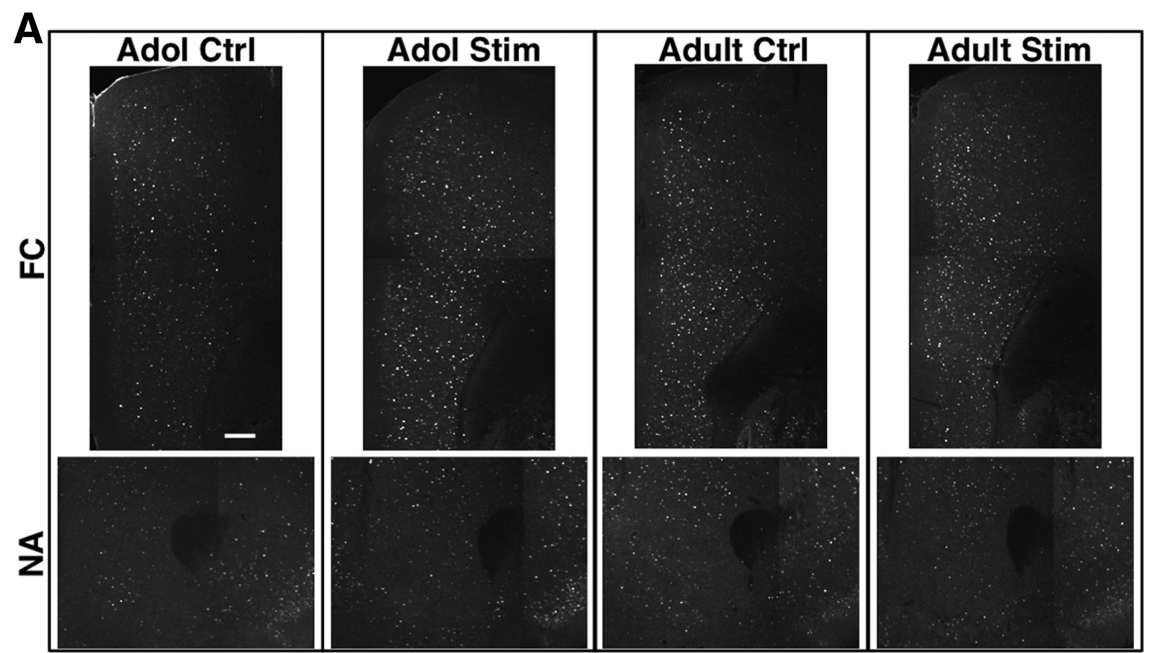

B

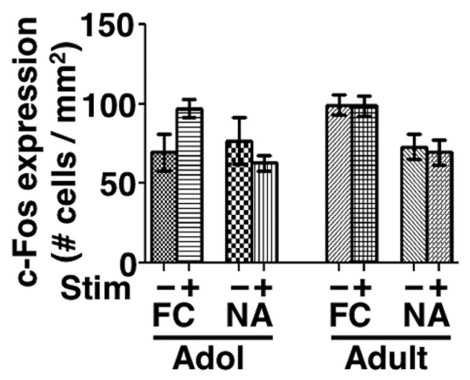

C

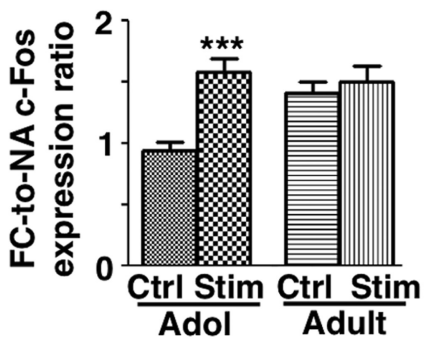

Figure 8. Phasic VTA activation led to enhanced c-Fos expression in FC versus NA in adolescence. $\boldsymbol{A}$, Confocal images of c-Fos immunofluorescence in $\mathrm{FC}$ and NA from mice after the amphetamine test. $\boldsymbol{B}$, The density of c-Fos ${ }^{+}$cells in FC and NA in brain sections collected 60 min after amphetamine exposure. $C$, The ratio of the density of c-Fos ${ }^{+}$cells in $F C$ versus NA was increased in the stimulated (ChR2-EYFP) compared with the control (EGFP) adolescent mice. ${ }^{* * *} p=0.0003$, Bonferroni's posttest; 2-way ANOVA age-by-treatment interaction, $F_{(1,28)}=7.06, p=0.013 . n=8$ mice each. Data are means \pm SE. Scale bar, $200 \mu \mathrm{m}$.

mesofrontal circuitry, including bouton changes detected by in vivo two-photon microscopy, electrophysiological changes detected by LFP recording, behavioral changes detected by psychomotor test, and brain activation pattern changes detected by c-Fos mapping. In contrast, in adult mice, although dopamine neurons are activated to comparable levels, the ensuing changes in the structure and function of mesofrontal circuitry diminish. Our study therefore provides direct evidence that the structure and function of the mesofrontal circuit is modifiable by phasic activation of dopamine neurons in adolescence. These adolescent changes are all causally linked to the phasic activity of dopamine neurons and consistent with each other. Together, they provide a multifaceted view of enhanced mesofrontal plasticity in adolescence across multiple biological levels.

At the structural level, this study delivers the first evidence that increasing the activity of dopamine neurons promotes the formation of mesofrontal boutons in adolescence. The rates of bouton dynamics we found, which are expressed as percentages of preexisting structures, are within the range (from a few percentages at baseline level to tens of percentage after activity perturbation) reported in previous in vivo imaging studies of glutamatergic or GABAergic axons (Holtmaat et al., 2009; Fu and Zuo, 2011). We did not find any significant effect on bouton elimination rates, although any reduction from the low baseline rate may require higher bouton sampling to detect. In contrast, our results revealed significantly increased bouton formation in response to phasic activation of dopamine neurons in adolescence. These find- ings suggest a causal role of phasic firing in strengthening the mesofrontal innervation during adolescence.

Phasic activity in dopamine neurons is naturally induced by reward-related or motivationally salient events, whereas tonic activity occurs spontaneously in these neurons (Grace et al., 2007; Schultz, 2007; Bromberg-Martin et al., 2010). Our initial findings showed that wheel running, a natural behavior that increases the phasic activity of VTA neurons (Wang and Tsien, 2011), promoted mesofrontal bouton formation in adolescence. We then used light pulses mimicking the natural activity patterns of dopamine neurons to examine the causal roles of those patterns in driving the structural changes of mesofrontal axons. In contrast to phasic activity, tonic activation of dopamine neurons with the same number of light pulses did not have any effect on the structure of adolescent mesofrontal axons. These results suggest that the temporal pattern of neural activity, rather than the total amount, is important for structural changes in this circuit. Moreover, our results imply a unique role of motivationally salient events in triggering structural changes in the mesoprefrontal circuit during adolescent development.

We found that the structural plasticity of mesofrontal axons induced by phasic dopamine neuron activity is significantly higher in adolescence than that in adulthood. Moreover, this plasticity can be modulated bidirectionally by D2R signaling. D2R has both presynaptic and postsynaptic localization and functions (Anzalone et al., 2012). However, in contrast to dopamine neurons projecting to other brain regions such as striatum, the mesocortical dopaminergic neurons in mouse VTA appear to lack D2R (Lammel et al., 2008). In our study, therefore, the effects of D2R agonist and antagonist may be mediated by D2R located in the FC. Interestingly, earlier electrophysiological studies have reported that D2R modulation of prefrontal neural activity becomes stronger in adults than in adolescents (Tseng and O'Donnell, 2007a, 2007b). Our results showed that, in adolescent mice, increasing D2R activation suppresses the high rate of bouton formation induced by phasic activity. In adult mice, conversely, decreasing D2R activation restores this structural plasticity. Those results suggest that age-related changes in D2R-signaling pathways may contribute to the difference in axonal plasticity between adolescents and adults.

The axonal changes we found here are long lasting and correlate with subsequent changes in frontal circuit activity. Previous studies have shown consistent associations between changes in dopaminergic axons and dopamine release in the FC. For example, the gradual development of dopaminergic axons in the FC correlates with a steady increase in dopamine levels (Niwa et al., 2010; Naneix et al., 2012), and genetic perturbations of dopaminergic innervation also lead to corresponding changes in frontal dopamine (Grant et al., 2009; Niwa et al., 2010; Manitt et al., 2011). The magnitude of structural change we found here $(\sim 20 \%$ 
increase in bouton formation) is in the tens-of-percentage range observed in those earlier studies. Moreover, our results showed that the increased mesofrontal innervation is associated with a prolonged frontal LFP response containing high-frequency oscillations, which is characteristic of elevated dopaminergic signaling (Lewis and O'Donnell, 2000; Seamans et al., 2003; Gireesh and Plenz, 2008; Wood et al., 2012). In addition, the extent of c-Fos expression in response to amphetamine is also increased in frontal cortical neurons. Together, those findings suggest that the structural changes we observed in dopaminergic axons are likely translated into postsynaptic effects.

Our imaging and electrophysiological results demonstrate that phasic dopamine neuron activity during adolescence elicits unique structural and functional plasticity in the mesofrontal circuit compared with that during adulthood. Previous studies of phasic dopamine neuron activity have focused on its roles in eliciting reward- or aversion-related behaviors in adulthood (Tsai et al., 2009; Zweifel et al., 2009; Lammel et al., 2012; Chaudhury et al., 2013; Tye et al., 2013). Our findings showed that phasic dopamine neuron activity modulates behavioral patterns differently between adolescence and adulthood. In adolescent mice, phasic VTA activation led to increased mesofrontal activation and suppressed psychomotor response in subsequent behavioral tests, which is consistent with the inhibitory role of the mesofrontal circuit in psychomotor activity (Tzschentke, 2001; Flores et al., 2005; Niwa et al., 2013). In contrast, in adult mice, the impacts of phasic VTA activation on the mesofrontal circuit and psychomotor behavior both diminished. Our findings may provide an initial step toward elucidating the effects of adolescent neural perturbation on behavioral patterns relevant to neuropsychiatric disorders.

Separate populations of VTA dopamine neurons project to FC and NA, which may exert competing influences on animal behavior (Björklund and Dunnett, 2007; Lammel et al., 2008; Lammel et al., 2012). In addition, it has been suggested that FC and NA have different maturation trajectories (Casey et al., 2010; Wahlstrom et al., 2010; Naneix et al., 2012). In adolescent mice that received prior phasic VTA stimulation, we found a higher FCto-NA c-Fos activation ratio than in those that received no stimulation. This observation raises the possibility that the mesofrontal dopaminergic circuit might be more malleable to the effects of phasic activation than the mesoaccumbens circuit in adolescence, which would be an interesting topic for future investigation using new optical imaging and modulation techniques to access both pathways (Deisseroth and Schnitzer, 2013).

Based on age-specific changes in behavior traits, body growth, sexual maturation, and neurobiological characteristics, an age range from $\sim \mathrm{P} 28-\mathrm{P} 42$ is suggested to represent the central adolescent period in rodents (Spear, 2000). Some adolescencerelated ontogenetic changes, though, appear to emerge as early as P21 and last until P56 or so (Laviola et al., 2003; Ernst et al., 2009; Brenhouse and Andersen, 2011). In the mesofrontal circuit, dopaminergic innervation shows a protracted development from P21 to P56 (Kalsbeek et al., 1988; Niwa et al., 2010; Naneix et al., 2012) and dopamine's effects on frontal neural activity change rapidly over the late adolescence period ( P45-P50; Tseng and O'Donnell, 2005, 2007a). Because we aimed to investigate the differences in mesofrontal plasticity over adolescence, we chose a relatively early adolescent period $(\sim 4-5$ weeks, P28-P42) to provide a greater contrast with the adult period (2-4 months). Future studies including additional time points will provide a more detailed view of adolescent transitions.
Human studies suggest that dysfunctions in mesofrontal dopaminergic circuit are associated with adolescent-onset psychiatric disorders such as schizophrenia, $\mathrm{ADHD}$, and addiction, and adolescent experience is proposed to be a critical factor (Lewis and Levitt, 2002; Chambers et al., 2003; Winterer and Weinberger, 2004; Casey et al., 2010). Neuropsychological studies have also suggested adolescent period as amendable for rapid changes in cognitive functions and motivational control (Chambers et al., 2003; Casey et al., 2010). Our analyses in mice show that the mesofrontal dopaminergic circuit exhibits unique plasticity in adolescence and is more susceptible to activity-dependent modification during this period than adulthood. Therapeutic brain stimulation strategies delivered at this age may therefore achieve potentially greater effect than that at adulthood. In addition, our findings show that combining brain stimulation with D2R antagonism, which is implicated in antipsychotic drug actions, can restore adult structural plasticity in the mesofrontal circuit. This result may help raise interest in exploring the joint effects of pharmacological and electrical treatment strategies. Our integrated optogenetic modulation and monitoring system may serve as a starting point for identifying molecular targets involved in activity-driven neurobiological changes during adolescence and for testing the potential impacts of therapeutic strategies on this circuit.

\section{References}

Andrasfalvy BK, Zemelman BV, Tang J, Vaziri A (2010) Two-photon singlecell optogenetic control of neuronal activity by sculpted light. Proc Natl Acad Sci U S A 107:11981-11986. CrossRef Medline

Anzalone A, Lizardi-Ortiz JE, Ramos M, De Mei C, Hopf FW, Iaccarino C, Halbout B, Jacobsen J, Kinoshita C, Welter M, Caron MG, Bonci A, Sulzer D, Borrelli E (2012) Dual control of dopamine synthesis and release by presynaptic and postsynaptic dopamine D2 receptors. J Neurosci 32: 9023-9034. CrossRef Medline

Bekar L, Libionka W, Tian GF, Xu Q, Torres A, Wang X, Lovatt D, Williams E, Takano T, Schnermann J, Bakos R, Nedergaard M (2008) Adenosine is crucial for deep brain stimulation-mediated attenuation of tremor. Nat Med 14:75-80. CrossRef Medline

Berger B, Gaspar P, Verney C (1991) Dopaminergic innervation of the cerebral cortex: unexpected differences between rodents and primates. Trends Neurosci 14:21-27. CrossRef Medline

Björklund A, Dunnett SB (2007) Dopamine neuron systems in the brain: an update. Trends Neurosci 30:194-202. CrossRef Medline

Brenhouse HC, Andersen SL (2011) Developmental trajectories during adolescence in males and females: a cross-species understanding of underlying brain changes. Neurosci Biobehav Rev 35:1687-1703. CrossRef Medline

Bromberg-Martin ES, Matsumoto M, Hikosaka O (2010) Dopamine in motivational control: rewarding, aversive, and alerting. Neuron 68:815-834. CrossRef Medline

Buzsáki G, Anastassiou CA, Koch C (2012) The origin of extracellular fields and currents-EEG, ECoG, LFP and spikes. Nat Rev Neurosci 13:407-420. CrossRef Medline

Cao VY, Ye Y, Mastwal SS, Lovinger DM, Costa RM, Wang KH (2013) In vivo two-photon imaging of experience-dependent molecular changes in cortical neurons. J Vis Exp pii:50148. CrossRef Medline

Casey BJ, Duhoux S, Malter Cohen M (2010) Adolescence: what do transmission, transition, and translation have to do with it? Neuron 67:749760. CrossRef Medline

Chambers RA, Taylor JR, Potenza MN (2003) Developmental neurocircuitry of motivation in adolescence: a critical period of addiction vulnerability. Am J Psychiatry 160:1041-1052. CrossRef Medline

Chaudhury D, Walsh JJ, Friedman AK, Juarez B, Ku SM, Koo JW, Ferguson D, Tsai HC, Pomeranz L, Christoffel DJ, Nectow AR, Ekstrand M, Domingos A, Mazei-Robison MS, Mouzon E, Lobo MK, Neve RL, Friedman JM, Russo SJ, Deisseroth K, et al. (2013) Rapid regulation of depressionrelated behaviours by control of midbrain dopamine neurons. Nature 493:532-536. CrossRef Medline

Costa RM, Lin SC, Sotnikova TD, Cyr M, Gainetdinov RR, Caron MG, Ni- 
colelis MA (2006) Rapid alterations in corticostriatal ensemble coordination during acute dopamine-dependent motor dysfunction. Neuron 52:359-369. CrossRef Medline

Deisseroth K, Schnitzer MJ (2013) Engineering approaches to illuminating brain structure and dynamics. Neuron 80:568-577. CrossRef Medline

Deng JV, Rodriguiz RM, Hutchinson AN, Kim IH, Wetsel WC, West AE (2010) MeCP2 in the nucleus accumbens contributes to neural and behavioral responses to psychostimulants. Nat Neurosci 13:1128-1136. CrossRef Medline

De Paola V, Holtmaat A, Knott G, Song S, Wilbrecht L, Caroni P, Svoboda K (2006) Cell type-specific structural plasticity of axonal branches and boutons in the adult neocortex. Neuron 49:861-875. CrossRef Medline

Di Salvio M, Di Giovannantonio LG, Acampora D, Prosperi R, Omodei D, Prakash N, Wurst W, Simeone A (2010) Otx2 controls neuron subtype identity in ventral tegmental area and antagonizes vulnerability to MPTP. Nat Neurosci 13:1481-1488. CrossRef Medline

Ernst M, Romeo RD, Andersen SL (2009) Neurobiology of the development of motivated behaviors in adolescence: a window into a neural systems model. Pharmacol Biochem Behav 93:199-211. CrossRef Medline

Fields HL, Hjelmstad GO, Margolis EB, Nicola SM (2007) Ventral tegmental area neurons in learned appetitive behavior and positive reinforcement. Annu Rev Neurosci 30:289-316. CrossRef Medline

Flores C, Manitt C, Rodaros D, Thompson KM, Rajabi H, Luk KC, Tritsch NX, Sadikot AF, Stewart J, Kennedy TE (2005) Netrin receptor deficient mice exhibit functional reorganization of dopaminergic systems and do not sensitize to amphetamine. Mol Psychiatry 10:606-612. CrossRef Medline

Fu M, Zuo Y (2011) Experience-dependent structural plasticity in the cortex. Trends Neurosci 34:177-187. CrossRef Medline

Furth KE, Mastwal S, Wang KH, Buonanno A, Vullhorst D (2013) Dopamine, cognitive function, and gamma oscillations: role of $\mathrm{D} 4$ receptors. Front Cell Neurosci 7:102. CrossRef Medline

Gireesh ED, Plenz D (2008) Neuronal avalanches organize as nested thetaand beta/gamma-oscillations during development of cortical layer 2/3. Proc Natl Acad Sci U S A 105:7576-7581. CrossRef Medline

Gong S, Doughty M, Harbaugh CR, Cummins A, Hatten ME, Heintz N, Gerfen CR (2007) Targeting Cre recombinase to specific neuron populations with bacterial artificial chromosome constructs. J Neurosci 27: 9817-9823. CrossRef Medline

Grace AA, Floresco SB, Goto Y, Lodge DJ (2007) Regulation of firing of dopaminergic neurons and control of goal-directed behaviors. Trends Neurosci 30:220-227. CrossRef Medline

Grant A, Speed Z, Labelle-Dumais C, Flores C (2009) Post-pubertal emergence of a dopamine phenotype in netrin-1 receptor-deficient mice. Eur J Neurosci 30:1318-1328. CrossRef Medline

Holtmaat A, Bonhoeffer T, Chow DK, Chuckowree J, De Paola V, Hofer SB, Hübener M, Keck T, Knott G, Lee WC, Mostany R, Mrsic-Flogel TD, Nedivi E, Portera-Cailliau C, Svoboda K, Trachtenberg JT, Wilbrecht L (2009) Long-term, high-resolution imaging in the mouse neocortex through a chronic cranial window. Nat Protoc 4:1128-1144. CrossRef Medline

Kalsbeek A, Voorn P, Buijs RM, Pool CW, Uylings HB (1988) Development of the dopaminergic innervation in the prefrontal cortex of the rat. J Comp Neurol 269:58-72. CrossRef Medline

Lammel S, Hetzel A, Häckel O, Jones I, Liss B, Roeper J (2008) Unique properties of mesoprefrontal neurons within a dual mesocorticolimbic dopamine system. Neuron 57:760-773. CrossRef Medline

Lammel S, Lim BK, Ran C, Huang KW, Betley MJ, Tye KM, Deisseroth K, Malenka RC (2012) Input-specific control of reward and aversion in the ventral tegmental area. Nature 491:212-217. CrossRef Medline

Lavin A, Nogueira L, Lapish CC, Wightman RM, Phillips PE, Seamans JK (2005) Mesocortical dopamine neurons operate in distinct temporal domains using multimodal signaling. J Neurosci 25:5013-5023. CrossRef Medline

Laviola G, Macrì S, Morley-Fletcher S, Adriani W (2003) Risk-taking behavior in adolescent mice: psychobiological determinants and early epigenetic influence. Neurosci Biobehav Rev 27:19-31. CrossRef Medline

Le Moal M, Simon H (1991) Mesocorticolimbic dopaminergic network: functional and regulatory roles. Physiol Rev 71:155-234. Medline

Lewis BL, O’Donnell P (2000) Ventral tegmental area afferents to the prefrontal cortex maintain membrane potential 'up' states in pyramidal neu- rons via $\mathrm{D}(1)$ dopamine receptors. Cereb Cortex 10:1168-1175. CrossRef Medline

Lewis DA, Levitt P (2002) Schizophrenia as a disorder of neurodevelopment. Annu Rev Neurosci 25:409-432. CrossRef Medline

Manitt C, Mimee A, Eng C, Pokinko M, Stroh T, Cooper HM, Kolb B, Flores C (2011) The netrin receptor DCC is required in the pubertal organization of mesocortical dopamine circuitry. J Neurosci 31:8381-8394. CrossRef Medline

McAllister AK (2007) Dynamic aspects of CNS synapse formation. Annu Rev Neurosci 30:425-450. CrossRef Medline

Naneix F, Marchand AR, Di Scala G, Pape JR, Coutureau E (2012) Parallel maturation of goal-directed behavior and dopaminergic systems during adolescence. J Neurosci 32:16223-16232. CrossRef Medline

Nishiyama H, Fukaya M, Watanabe M, Linden DJ (2007) Axonal motility and its modulation by activity are branch-type specific in the intact adult cerebellum. Neuron 56:472-487. CrossRef Medline

Niwa M, Kamiya A, Murai R, Kubo K, Gruber AJ, Tomita K, Lu L, Tomisato S, Jaaro-Peled H, Seshadri S, Hiyama H, Huang B, Kohda K, Noda Y, O’Donnell P, Nakajima K, Sawa A, Nabeshima T (2010) Knockdown of DISC1 by in utero gene transfer disturbs postnatal dopaminergic maturation in the frontal cortex and leads to adult behavioral deficits. Neuron 65:480-489. CrossRef Medline

Niwa M, Jaaro-Peled H, Tankou S, Seshadri S, Hikida T, Matsumoto Y, Cascella NG, Kano S, Ozaki N, Nabeshima T, Sawa A (2013) Adolescent stress-induced epigenetic control of dopaminergic neurons via glucocorticoids. Science 339:335-339. CrossRef Medline

Onn SP, Wang XB (2005) Differential modulation of anterior cingulate cortical activity by afferents from ventral tegmental area and mediodorsal thalamus. Eur J Neurosci 21:2975-2992. CrossRef Medline

Papagiakoumou E, Anselmi F, Bègue A, de Sars V, Glückstad J, Isacoff EY, Emiliani V (2010) Scanless two-photon excitation of channelrhodopsin-2. Nat Methods 7:848-854. CrossRef Medline

Parish CL, Finkelstein DI, Drago J, Borrelli E, Horne MK (2001) The role of dopamine receptors in regulating the size of axonal arbors. J Neurosci 21:5147-5157. Medline

Parish CL, Stanic D, Drago J, Borrelli E, Finkelstein DI, Horne MK (2002) Effects of long-term treatment with dopamine receptor agonists and antagonists on terminal arbor size. Eur J Neurosci 16:787-794. CrossRef Medline

Paxinos G, Franklin KBJ (2004) The mouse brain in stereotaxic coordinates, Ed 2. Amsterdam, Boston: Elsevier Academic.

Rickgauer JP, Tank DW (2009) Two-photon excitation of channelrhodopsin-2 at saturation. Proc Natl Acad Sci U S A 106:15025-15030. CrossRef Medline

Riekkinen M, Stefanski R, Kuitunen J, Riekkinen P Jr (1996) Effects of combined block of alpha 1-adrenoceptors and NMDA receptors on spatial and passive avoidance behavior in rats. Eur J Pharmacol 300:9-16. CrossRef Medline

Rosenberg DR, Lewis DA (1995) Postnatal maturation of the dopaminergic innervation of monkey prefrontal and motor cortices: a tyrosine hydroxylase immunohistochemical analysis. J Comp Neurol 358:383-400. CrossRef Medline

Sato Y, Nakajima S, Shiraga N, Atsumi H, Yoshida S, Koller T, Gerig G, Kikinis R (1998) Three-dimensional multi-scale line filter for segmentation and visualization of curvilinear structures in medical images. Med Image Anal 2:143-168. CrossRef Medline

Schultz W (2007) Multiple dopamine functions at different time courses. Annu Rev Neurosci 30:259-288. CrossRef Medline

Seamans JK, Nogueira L, Lavin A (2003) Synaptic basis of persistent activity in prefrontal cortex in vivo and in organotypic cultures. Cereb Cortex 13:1242-1250. CrossRef Medline

Spear LP (2000) The adolescent brain and age-related behavioral manifestations. Neurosci Biobehav Rev 24:417-463. CrossRef Medline

Stuber GD, Hnasko TS, Britt JP, Edwards RH, Bonci A (2010) Dopaminergic terminals in the nucleus accumbens but not the dorsal striatum corelease glutamate. J Neurosci 30:8229-8233. CrossRef Medline

Sulzer D, Joyce MP, Lin L, Geldwert D, Haber SN, Hattori T, Rayport S (1998) Dopamine neurons make glutamatergic synapses in vitro. J Neurosci 18:4588-4602. Medline

Tsai HC, Zhang F, Adamantidis A, Stuber GD, Bonci A, de Lecea L, Deisseroth K (2009) Phasic firing in dopaminergic neurons is sufficient for behavioral conditioning. Science 324:1080-1084. CrossRef Medline

Tseng KY, O’Donnell P (2005) Post-pubertal emergence of prefrontal 
cortical up states induced by D1-NMDA co-activation. Cereb Cortex 15:49-57. CrossRef Medline

Tseng KY, O’Donnell P (2007a) Dopamine modulation of prefrontal cortical interneurons changes during adolescence. Cereb Cortex 17:12351240. CrossRef Medline

Tseng KY, O'Donnell P (2007b) D2 dopamine receptors recruit a GABA component for their attenuation of excitatory synaptic transmission in the adult rat prefrontal cortex. Synapse 61:843-850. CrossRef Medline

Tye KM, Deisseroth K (2012) Optogenetic investigation of neural circuits underlying brain disease in animal models. Nat Rev Neurosci 13:251-266. CrossRef Medline

Tye KM, Mirzabekov JJ, Warden MR, Ferenczi EA, Tsai HC, Finkelstein J, Kim SY, Adhikari A, Thompson KR, Andalman AS, Gunaydin LA, Witten IB, Deisseroth K (2013) Dopamine neurons modulate neural encoding and expression of depression-related behaviour. Nature 493:537-541. CrossRef Medline

Tzschentke TM (2001) Pharmacology and behavioral pharmacology of the mesocortical dopamine system. Prog Neurobiol 63:241-320. CrossRef Medline

Wahlstrom D, White T, Luciana M (2010) Neurobehavioral evidence for changes in dopamine system activity during adolescence. Neurosci Biobehav Rev 34:631-648. CrossRef Medline
Wang DV, Tsien JZ (2011) Conjunctive processing of locomotor signals by the ventral tegmental area neuronal population. PLoS One 6:e16528. CrossRef Medline

Wang KH, Majewska A, Schummers J, Farley B, Hu C, Sur M, Tonegawa S (2006) In vivo two-photon imaging reveals a role of arc in enhancing orientation specificity in visual cortex. Cell 126:389-402. CrossRef Medline

Winterer G, Weinberger DR (2004) Genes, dopamine and cortical signalto-noise ratio in schizophrenia. Trends Neurosci 27:683-690. CrossRef Medline

Wood J, Kim Y, Moghaddam B (2012) Disruption of prefrontal cortex large scale neuronal activity by different classes of psychotomimetic drugs. J Neurosci 32:3022-3031. CrossRef Medline

Zhang T, Zhang L, Liang Y, Siapas AG, Zhou FM, Dani JA (2009) Dopamine signaling differences in the nucleus accumbens and dorsal striatum exploited by nicotine. J Neurosci 29:4035-4043. CrossRef Medline

Zhang YP, Oertner TG (2007) Optical induction of synaptic plasticity using a light-sensitive channel. Nat Methods 4:139-141. CrossRef Medline

Zweifel LS, Parker JG, Lobb CJ, Rainwater A, Wall VZ, Fadok JP, Darvas M, Kim MJ, Mizumori SJ, Paladini CA, Phillips PE, Palmiter RD (2009) Disruption of NMDAR-dependent burst firing by dopamine neurons provides selective assessment of phasic dopamine-dependent behavior. Proc Natl Acad Sci U S A 106:7281-7288. CrossRef Medline 